

\section{Wind Plant Ramping Behavior}

Erik Ela

National Renewable Energy Laboratory

Jason Kemper

Northern Arizona University

Prepared under Task No. WER8.5102
Technical Report NREL/TP-550-46938

December 2009

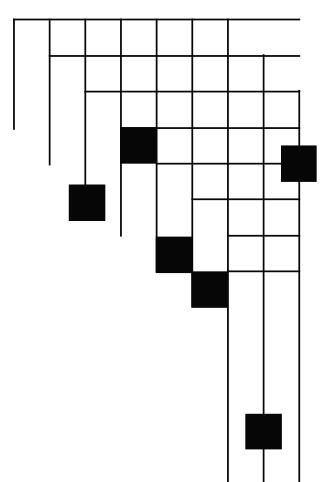

National Renewable Energy Laboratory 1617 Cole Boulevard, Golden, Colorado 80401-3393 303-275-3000 • www.nrel.gov

NREL is a national laboratory of the U.S. Department of Energy Office of Energy Efficiency and Renewable Energy

Operated by the Alliance for Sustainable Energy, LLC

Contract No. DE-AC36-08-GO28308 


\section{NOTICE}

This report was prepared as an account of work sponsored by an agency of the United States government. Neither the United States government nor any agency thereof, nor any of their employees, makes any warranty, express or implied, or assumes any legal liability or responsibility for the accuracy, completeness, or usefulness of any information, apparatus, product, or process disclosed, or represents that its use would not infringe privately owned rights. Reference herein to any specific commercial product, process, or service by trade name, trademark, manufacturer, or otherwise does not necessarily constitute or imply its endorsement, recommendation, or favoring by the United States government or any agency thereof. The views and opinions of authors expressed herein do not necessarily state or reflect those of the United States government or any agency thereof.

Available electronically at http://www.osti.gov/bridge

Available for a processing fee to U.S. Department of Energy and its contractors, in paper, from:

U.S. Department of Energy

Office of Scientific and Technical Information

P.O. Box 62

Oak Ridge, TN 37831-0062

phone: 865.576 .8401

fax: 865.576 .5728

email: mailto:reports@adonis.osti.gov

Available for sale to the public, in paper, from:

U.S. Department of Commerce

National Technical Information Service

5285 Port Royal Road

Springfield, VA 22161

phone: 800.553.6847

fax: 703.605.6900

email: orders@ntis.fedworld.gov

online ordering: http://www.ntis.gov/ordering.htm 


\section{Wind Plant Ramping Behavior}

\section{Table of Contents}

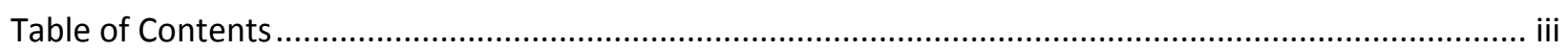

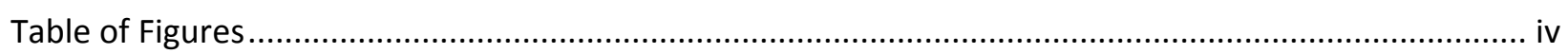

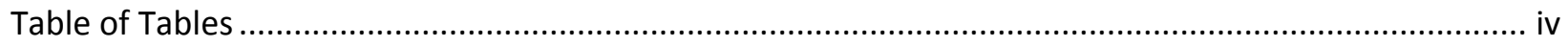

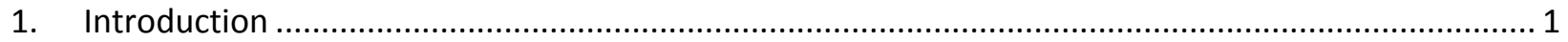

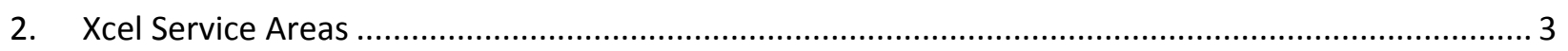

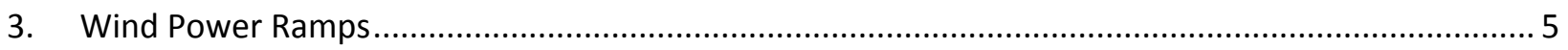

A. PSCO

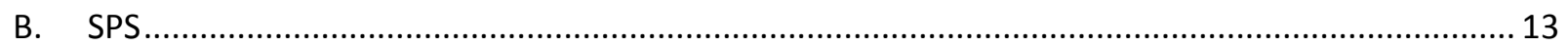

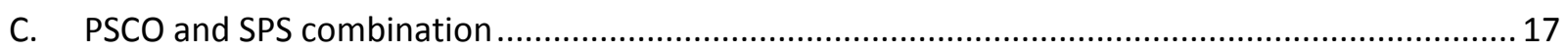

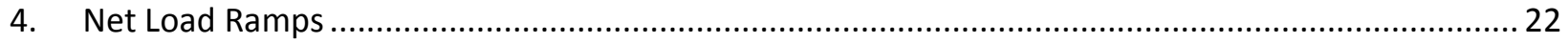

A. PSCO

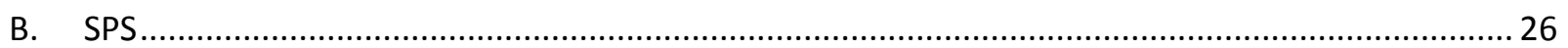

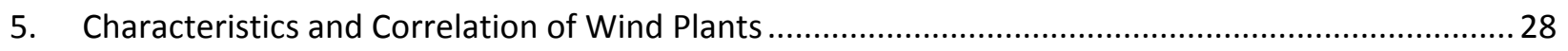

A. PSCO

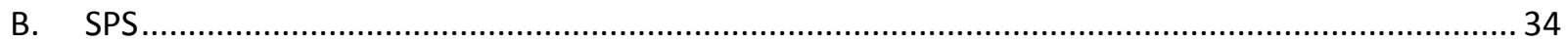

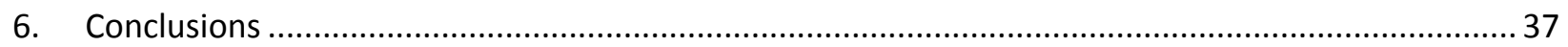

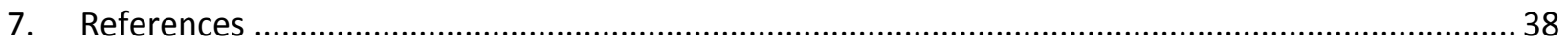




\section{Table of Figures}

Figure 1 - Power system time frames......

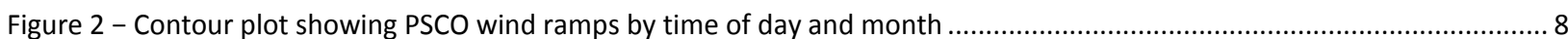

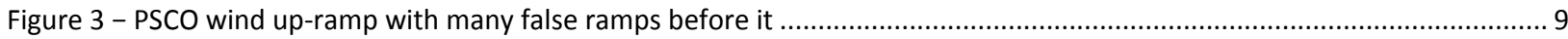

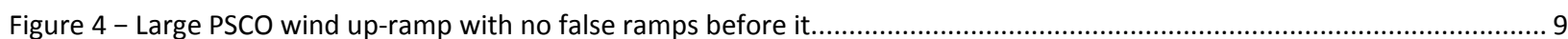

Figure 5 - Contributions from numerous PSCO wind plants during large down-ramp....................................................... 10

Figure 6 - Contributions from numerous PSCO wind plants during large up-ramp........................................................... 11

Figure 7 - Up-ramp showing easterly Logan increasing before cedar creek …..................................................................... 12

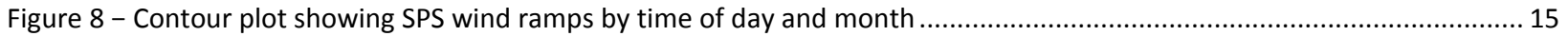

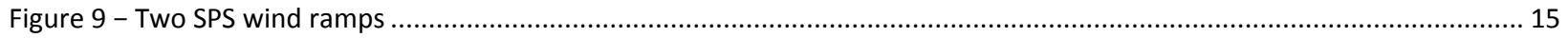

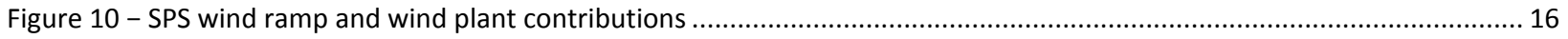

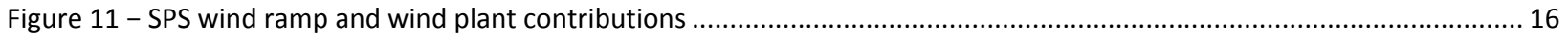

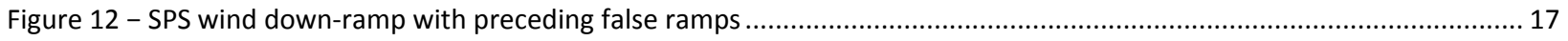

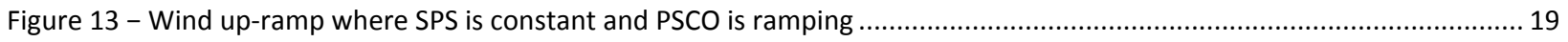

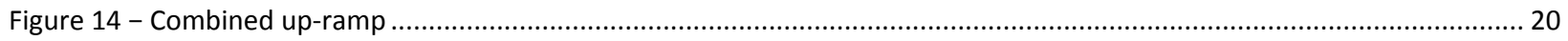

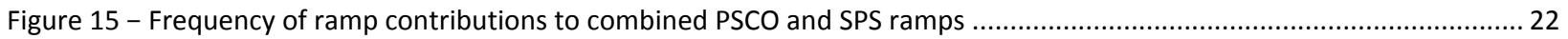

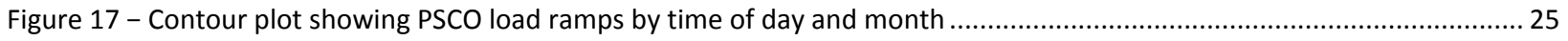

Figure 18 - Contour plot showing PSCO net load ramps by time of day and month............................................................25

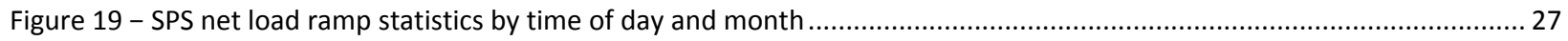

Figure 20 - Correlations between PSCO wind power plants during ramp periods and all times...............................................29

Figure 21 - Step change correlations for PSCO during all times and ramp events ................................................................ 31

Figure 22 - Cross-correlations between Cedar Creek and PSCO wind plants as a function of a temporal shift ........................... 32

Figure 23 - Cross-correlations between Logan and PSCO wind plants as a function of a temporal shift................................... 32

Figure 24 - Cross-correlations between Logan and PSCO wind plants as a function of a temporal shift during ramp periods ..... 33

Figure 25 - Cross-correlations between Logan and PSCO wind plants as a function of time shift during system-wide up- and

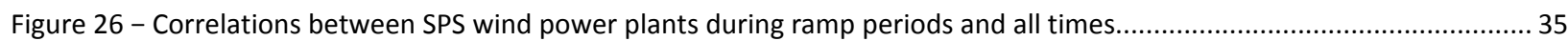

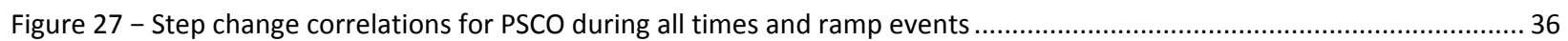

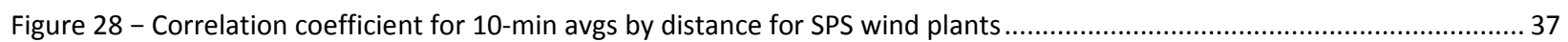

\section{Table of Tables}

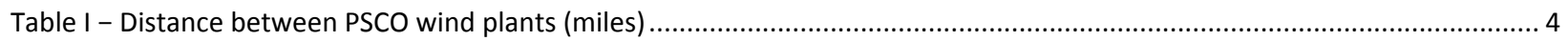

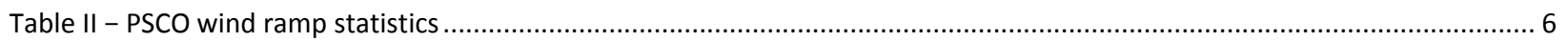

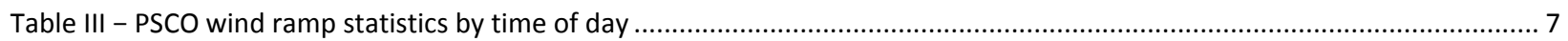

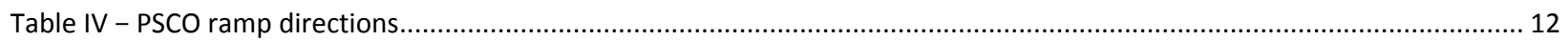

Table V - Individual wind plant ramps aligning or opposing system-wide wind ramps.......................................................... 13

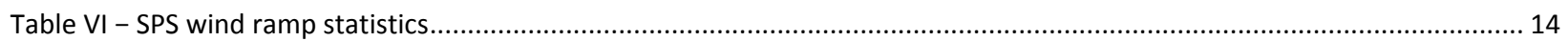

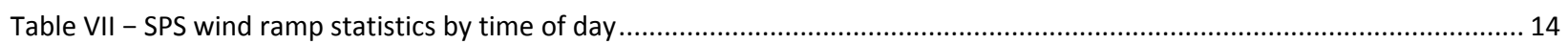

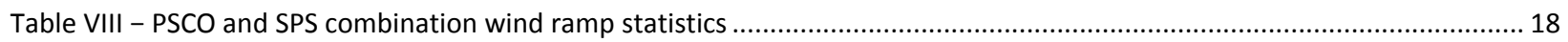

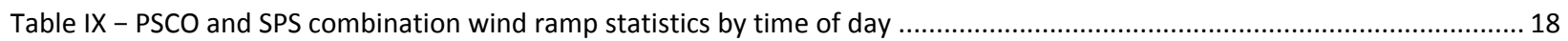

Table $X$ - Frequency of contributions from PSCO and SPS toward combined ramps'..........................................................2 21

Table XI - Frequency of contributions from PSCO and SPS toward combined ramps, normalized to region capacity .................. 21

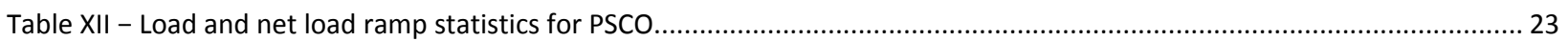

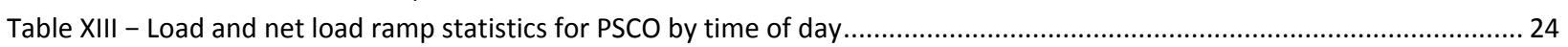

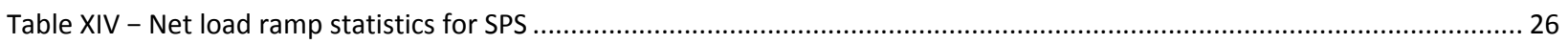

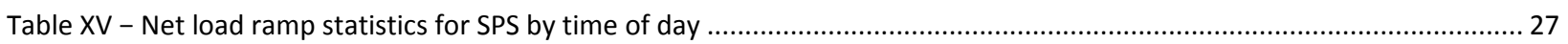

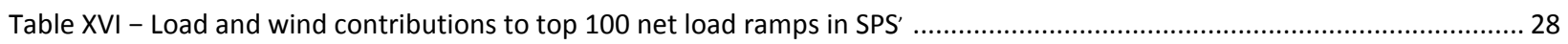

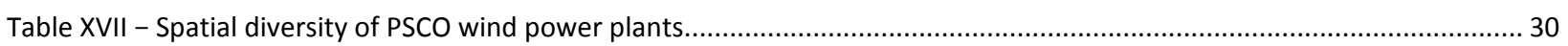

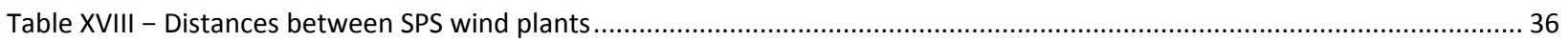




\section{Introduction}

Wind power plants are becoming a much greater contributor to the national electrical energy mixture. In recent years, economies of scale have made large areas with hundreds or more megawatt-size turbines economic and practical. Xcel Energy, based in Minneapolis, Minnesota, has one of the largest amounts of wind capacity in the United States. According to [1], there were 2,906 MW of nameplate capacity distributed between Xcel's three service territories at the end of 2008. Some reasons for the large amounts of wind being introduced in Xcel and other areas include its free fuel costs, zero emissions, and state RPS goals. With the increasing wind penetrations, utilities and Independent System Operators (ISO) are quickly trying to understand the impacts on system operations and planning.

One of the most important aspects of reliable power system operations is maintaining a balance between the demand and the generation used to meet the demand. Different time frames require different techniques of balancing the generation and load, as shown in Figure 1. In the unit commitment time frame, operations planners will turn on enough units to meet forecasted demand. This typically occurs between six hours and a few days ahead, and is performed to give long-start generating units sufficient time to start up and synchronize to the grid. Throughout the day, operators and traders will typically give hourly schedules to units and will make hourly trades between balancing area neighbors based on economics and often, updated information (i.e., better forecasts of outcomes). As real-time approaches, operators tend to adjust generator schedules in their areas to meet the quickly changing demand. This is often referred to as load-following, and units with sufficient ramping capabilities and units that can start quickly and synchronize to the grid are used to meet demand on a five-minute to one-hour time frame. Lastly, because random fluctuations occur in demand and can impact both the frequency of the power system as well as interconnection tie-line schedules, units that have "automatic generation control" (AGC) will rapidly adjust output to meet actual demand levels on a time frame of about every few seconds to a few minutes. Frequency that is too high or too low from its nominal level (i.e., $60 \mathrm{~Hz}$ in the United States) can cause varying issues and in the most drastic instance lead to load shedding or instability. Frequency is common to an interconnection, and control areas generally try to balance the generation and load in their much smaller balancing area. Therefore, area control error (ACE) is the more common measure of determining how well a control area is balancing its system. ACE measures the imbalance of generation of load by subtracting tie-line flows from their scheduled values and considers the frequency response of generation and load when frequency is not at its nominal level. 


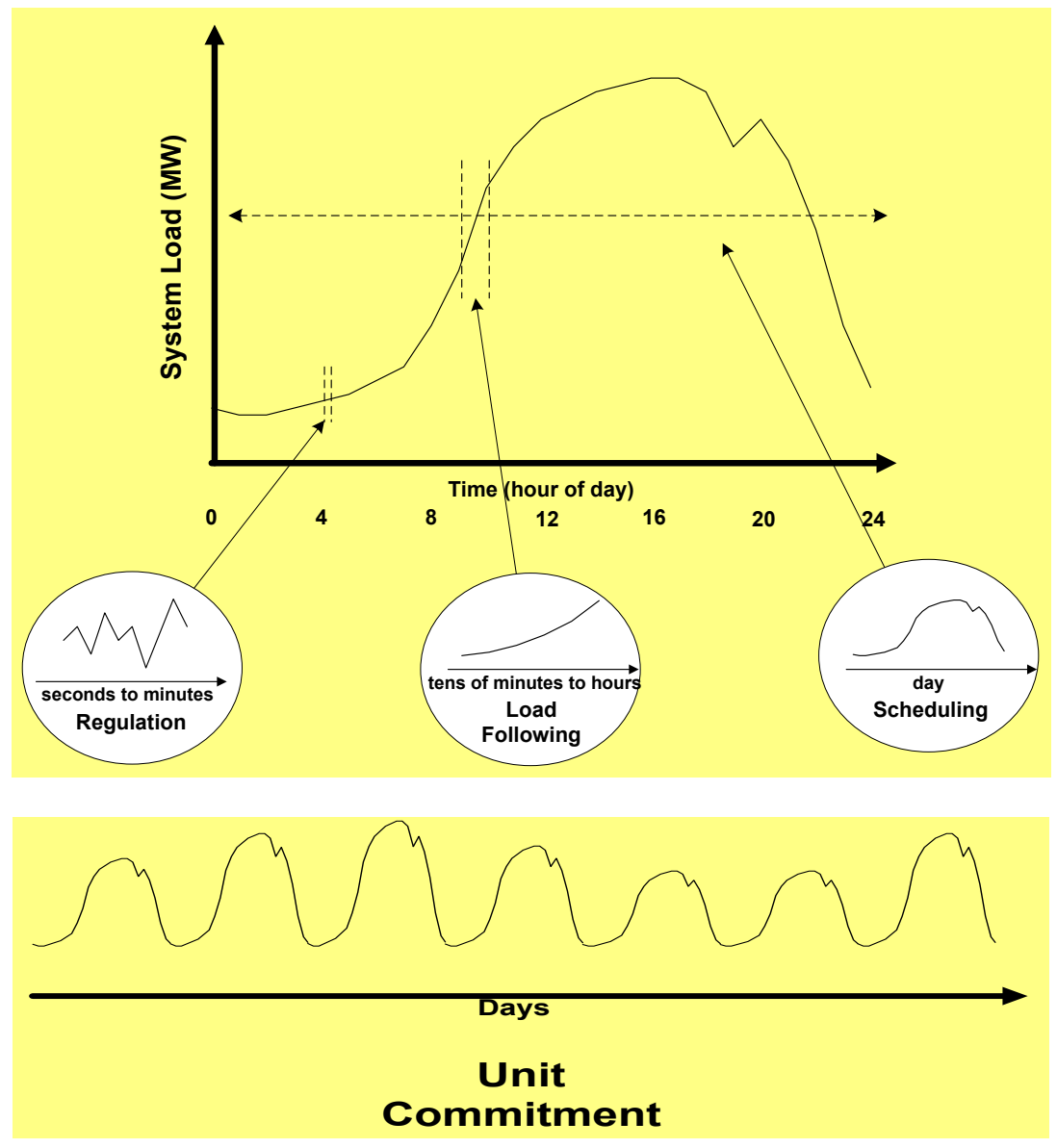

Figure 1 - Power system time frames

The techniques described are used primarily because of the variability and uncertainty of regional demand patterns. It is difficult to predict what the load demand will be ahead of time, and it often changes throughout the day. Wind power adds to these impacts with its own characteristics of variability and uncertainty. An understanding of how wind impacts the system has been a challenge for operators and planners, but much work has been done to improve this understanding. Wind power integration studies have been performed in various areas in the United States and Europe to simulate the power system with modeled wind data, and have quantified the operating impacts that occur [2]. Xcel Energy has performed integration studies in its Northern States Power (NSP) area [3] as well as its Public Service of Colorado (PSCO) area [4][5]. Wind plant data are usually represented by meso-scale weather models of past atmospheric conditions, and time series of these data are used in power system operations simulations. Operating impacts that drive ancillary service requirements as well as integration costs are typically extracted from the study. ${ }^{1}$ The studies provide tremendous value and give a better understanding of the characteristics and impacts of higher penetrations of wind power in a region. Real-time, high-resolution wind and power production data from systems such as those in Xcel

\footnotetext{
${ }^{1}$ Ancillary services include operating reserves and regulation reserves for these studies. Operating reserves are generally procured for use during system events like contingencies (e.g. generator failure and line outage) and regulation reserves are used for second-to-second variability of load and generation.
} 
Energy territories are becoming increasingly available, making it more feasible to evaluate the validity of these integration studies.

One universal conclusion from the studies and actual operations is that the proper use of wind power forecasting can significantly improve the integration of wind power by improving reliability and minimizing costs. Like load forecasting, wind forecasting can assist when making unit commitment decisions so that enough capacity is economically available to meet the next day's demand. Wind forecasting can also be used in more real-time operations to help adjust dispatch decisions and relieve network congestion. Wind forecasting can also assist in the determination of ancillary service requirements, economic trading of power between balancing areas or utilities, and for operational awareness of strong incoming weather events.

Strong weather events, though rare, can cause very large ramps in wind power that prove difficult for power system operators to manage. Forecasting large wind ramps is a new area of research, and many commercial providers of wind power forecasts are developing new methods to better predict these rare phenomena. Different regions of the world with different terrain and weather features can have very different ramping characteristics. In order to best predict these occurrences, the underlying meteorological conditions that drive wind power ramps must be well understood. Xcel Energy has teamed up with the National Center for Atmospheric Research (NCAR) and the National Renewable Energy Laboratory (NREL) to research ramping behavior and its impacts, and to develop a sophisticated wind prediction system for Xcel's service territories.

This research focused on the specific ramping behavior of two of Xcel's service territories, PSCO and Southwest Power System (SPS). Analysis using actual wind power data at high resolution was used to give a better understanding of typical behavior of the wind plants. The results were used to assist NCAR in using the power data of the ramps to investigate weather phenomena that were driving these events. The results also gave Xcel operators a better understanding of when and how different wind power ramps were occurring. A complete briefing on characteristics and behavior of wind power on various timescales and sizes can be found in [6].

The overall objective of this report is to give typical characteristics of large system-wide ramps and how correlations of wind plants and load can provide more information to a utility for predicting wind power ramps. This information will improve wind power ramp predictions and provide operators with better tools to integrate higher penetrations of wind power.

\section{Xcel Service Areas}

Xcel has three service areas in different parts of the country. Each area has a different market structure which leaves Xcel with different responsibilities for managing wind power in each area. Each area also has different patterns and concentrations of wind power on its system. This report will focus on the PSCO and SPS regions.

PSCO covers most of the state of Colorado. The area is not in an ISO market, so the responsibilities of unit commitment, balancing, ancillary services procurement and utilization, and tie-line scheduling fall 
within the utility's role. This means that there are both reliability and economic incentives for Xcel to manage the wind power on the system as efficiently as possible. In one study, Xcel found that by reducing the day-ahead forecast error of total wind power in PSCO by one percent $M A E^{2}$, total savings would be $\$ 1.2 \mathrm{M}$ per year[7]. ${ }^{3}$ Operators must constantly balance wind and load on the system and traders must know when it is most beneficial to trade energy with neighboring utilities. With large penetrations of wind, the understanding of how the wind will behave and when is a major driver of electricity prices and in some instances can affect the reliability of the system.

The best wind resources in PSCO are found in the northeastern and southeastern plains, and most of the wind plants are concentrated in these regions. In fact, more than $700 \mathrm{MW}$ of the approximately 1,060 $\mathrm{MW}$ of total wind capacity (about 2/3) is within 45 miles of each other in the northeast corner of Colorado. This concentration, shown in Table I, can cause difficulties because when large wind changes occur at one of these wind plants, the neighboring wind plants are often affected during similar time periods. This contributes to more severe wind ramps compared to areas with wind plants that are more spread out. Understanding the relationships between the wind plants in these areas is crucial to enhanced wind predictions of wind power ramping behavior.

Table I - Distance between PSCO wind plants (miles) ${ }^{4}$

\begin{tabular}{|l|r|r|r|r|r|r|}
\hline PSCO Wind Power Plant & PEET & PONN & SGCA & COLG & CEDC & \multicolumn{2}{l|}{ lOGA } \\
\hline PEET 29.7MW & 0 & 103 & 8 & 227 & 45 & 4 \\
\hline PONN 31.7MW & 103 & 0 & 110 & 207 & 66 & 100 \\
\hline SGCA 60MW & 8 & 110 & 0 & 228 & 53 & 12 \\
\hline COLG 237MW & 227 & 207 & 228 & 0 & 233 & 228 \\
\hline CEDC 300.5MW & 45 & 66 & 53 & 233 & 0 & 41 \\
\hline LOGA 400.5MW & 4 & 100 & 12 & 228 & 41 & 0 \\
\hline
\end{tabular}

SPS is located in the panhandle of Texas as well as parts of eastern New Mexico. The area is located within the Southwest Power Pool (SPP), an ISO that covers a large portion of the south central part of the United States [8]. Most ISOs have responsibilities to provide unit commitment for a day-ahead market, procure sufficient ancillary services, and send signals to resources within its borders to redispatch in times of network congestion or changing load. However, SPP only provides services related to re-dispatch. There is no day-ahead market or ancillary services market. The area of SPS is also in a very import-constrained part of SPP because there is little transmission capability to trade with other members of SPP. This means that even though there are responsibilities in the real-time for SPP to balance generation and load, there are still large responsibilities within SPS to commit units and provide ancillary service capabilities that make wind power ramps important for the area.

\footnotetext{
${ }^{2} \mathrm{MAE}$ is the mean absolute error usually defined as a percentage of nameplate capacity of the wind plant or collection of wind plants being evaluated. It is a common metric in defining the accuracy of a wind power forecast. ${ }^{3}$ With respect to the locations and total installed capacity of wind in 2008.

${ }^{4}$ Note that throughout this paper, the four letter representation of wind plants refers to the connection point on the respective system, and may be different than common representations of these wind plants
} 
The wind resources that are located in the SPS region include a larger number of smaller wind plants spread out through the region. As opposed to PSCO where large plants are located in close proximity, the smaller, more spread out plants in SPS tend to dampen the large wind ramp events. Significant weather events will take longer to reach multiple areas and may miss some areas all together. The results in the next section will quantify these findings further.

Northern States Power (NSP) is based in parts of Minnesota and Wisconsin. There is a large amount of installed wind capacity currently in this region and there are significant opportunities for Xcel to properly forecast wind output. However, this region lies fully in the Midwest Independent System Operator (MISO). MISO operates as a day 2 Regional Transmission Organization (RTO) and FERC-defined standard market design (SMD) [9][10]. This means that the normal responsibilities of day-ahead capacity planning and real-time dispatch over the MISO bulk power system are primarily under MISO control rather than the local utility. The importance of wind forecasting is still apparent to the utility, but the reliability aspects of wind power ramp forecasting are not as critical in this region as in the other two regions.

\section{Wind Power Ramps}

The main function of the joint project between Xcel, NCAR, and NREL is to develop a sophisticated wind prediction system that displays expected outputs of various wind plants to Xcel operators. At many times during the day, the wind is calm or steady, and its impacts on system operations are generally not significant. In terms of system reliability and costs, wind power forecast accuracy is most important during times when the wind power production is changing rapidly. During a wind down-ramp, an operator must compensate for the loss of generation by either ramping up other on-line generation, or by starting up a unit that is currently off-line. Conversely, a wind up-ramp must be compensated by ramping down units, shutting them off, or in some instances curtailing the high-producing wind. The different strategies are highly dependent on the speed (i.e., ramp rate), duration, magnitude, and timing of the ramp. It is also dependent on how far in advance the ramp is predicted. Different generating units have different characteristics: start-up times; ramping rates; minimum on and off times; and in some cases, energy limitations. Units with longer start times are usually cheaper to run than units with shorter start times. This is why predicting the event with confidence in advance can be very advantageous. Units with longer minimum on times are also generally cheaper to run than units with shorter minimum on times, assuming that the unit is needed for the entire minimum on time. This is why having a prediction of not only the duration of the ramp, but a prediction for how long the energy level of the wind is sustained following the ramp, can be very important. The magnitude and duration of the ramp can drive the capacity and energy requirements needed to compensate for the ramp. Finally, the ramp rate of a

wind ramp is an important prediction as well; this clearly drives the ramping rate needs of the compensating generation during the ramp event.

Objectively, identifying and ranking ramps is a difficult task. Given hourly averaged time-series data for power, examining the rates of change over one period (hour) may be sufficient for analysis. However, this level of resolution provides little useful information about what happened in real-time that a system operator had to handle. Thus, ten-minute (or less) averaged time-series data for power convey much more information. However, this resolution requires a method for defining a ramp that grows in 
complexity with increasing temporal resolution. Therefore, ramp defining tools were developed with two primary purposes in mind; the tools needed to be flexible to allow the user to define a ramp using multiple parameters and they needed to convey as much information regarding the ramp definition results as possible. Ramp defining tools were developed using Microsoft Excel and Matlab [11]. The tools allowed user-defined parameters, such as duration, ramp rate, and magnitude to determine when ramps had occurred. Once defined, all information for the observed ramps was displayed to the user and was used in this analysis.

\section{A. PSCO}

Definitions of the wind ramp events were developed for PSCO and the results for 2008 are presented below in Table II. ${ }^{5}$ Throughout this report, a ramp must exceed the magnitude in the defined duration period. Once this trigger is hit, the program determines the proper start and end time of the ramp event. For instance, if the ramp definition is $100 \mathrm{MW}$ for 60 minutes, the power would have to change by more than $100 \mathrm{MW}$ for any rolling 60-minute period. If this trigger was hit for consecutive intervals, the tool would only define one ramp rather than multiple. Start and end times were determined by a ten-minute period, either changing in direction or changing below some threshold (i.e., the ramp period had to be continuously changing above some level in order to be considered a continuous ramp. This level ranged from about $8-15 \mathrm{MW}$ for ten minutes depending on the size of the system.). This threshold was used so that large ramps that tapered off with changes of only a few MW would not receive excessive durations and misrepresent ramp rate values. Sensitivities were pursued where the duration could be defined with one or two very small rates of change, or even opposite rates of change inside a long ramp. This would change the average durations and would slightly change the total number of ramps. However, it was decided to use the one interval threshold to decide on start and end times for all ramp statistics for this analysis.

Table II - PSCO wind ramp statistics

\begin{tabular}{|l|l|l|l|l|l|}
\hline PSCO Wind = $1060 \mathrm{MW}$ & Total & Up & Down & Average duration & Max duration \\
\hline Ramps over $250(25 \%) \mathrm{MW}$ in $60 \mathrm{mins}$ & 353 & 203 & 150 & $77 \mathrm{~min}$ & $220 \mathrm{~min}$ \\
\hline Ramps over $350(33 \%) \mathrm{MW}$ in 60 mins & 91 & 63 & 28 & $67 \mathrm{~min}$ & $190 \mathrm{~min}$ \\
\hline Ramps over $500(50 \%) \mathrm{MW}$ in 60 mins & 15 & 13 & 2 & $49 \mathrm{~min}$ & $90 \mathrm{~min}$ \\
\hline Ramps over $250 \mathrm{MW}$ in 30 mins & 118 & 73 & 45 & $49 \mathrm{~min}$ & $150 \mathrm{~min}$ \\
\hline
\end{tabular}

\footnotetext{
${ }^{5}$ Depending on the data available at the time of analysis, this could either be Calendar year 2008, or some combination of late 2007 and 2008, but always encompassing 366 days of 10-minute data. This is true for all analysis throughout this report.
} 
One interesting observation from these results is that in all cases there are more occurrences of upramps compared to down-ramps. The more strict the ramp definition (i.e., the larger the threshold), the higher the percentage of up-ramps compared to down-ramps. For the 60-minute duration case, the percentage up-ramps versus down-ramps for $250 \mathrm{MW}, 350 \mathrm{MW}$, and $500 \mathrm{MW}$ is $58 \%, 69 \%$, and $87 \%$, respectively. This shows that the more significant the ramp definition, the higher the ratio of up- to down-ramps.

The total amounts of ramp events on the system show interesting results as well. The results indicate that a ramp greater than $25 \%$ of total generation in PSCO is likely to occur almost once per day. A ramp event greater than $50 \%$ of the total capacity, however, is likely to occur about once per month. The results also show that a typical ramp takes about one hour to complete, with the longest ramps in some instances lasting up to four hours.

Load demand has a pretty typical diurnal pattern depending on the season and whether it is a weekday or a weekend. Most load ramps occur in the morning when people are waking up, and in some instances, at night when people are turning on lights simultaneously. When wind ramps occur in the same direction as load ramps (i.e., they are both increasing or they are both decreasing), there is no cause for concern as they are helping to keep the system balanced and canceling out the impacts of the other. However, when the ramps are opposite in direction, the situation is exacerbated. The following table and figure are results for different six-hour periods of the day. Table III shows numbers, maximum ramp rates, and false ramp (false ramp is defined below) statistics. Figure 2 shows a contour plot of time of day and month ramping statistics.

Table III - PSCO wind ramp statistics by time of day ${ }^{6}$

\begin{tabular}{|l|l|l|l|l|l|}
\hline $\begin{array}{l}\text { Ramps over 250 } \\
\text { MW in 60 mins }\end{array}$ & Ramps & $\begin{array}{l}\text { Max 60 min } \\
\text { up ramp }\end{array}$ & $\begin{array}{l}\text { Max } 60 \mathrm{~min} \\
\text { down ramp }\end{array}$ & $\begin{array}{l}\text { Average false ramps (50 } \\
\text { MW in 10 min inside } \\
\text { five-hour window) }\end{array}$ & $\begin{array}{l}\text { Maximum false ramps } \\
\text { (50 MW in } 10 \text { min } \\
\text { inside five-hour } \\
\text { window) }\end{array}$ \\
\hline Hours 0 - 5 & 74 & $564 \mathrm{MW}$ & -422 & 0.66 & 4 \\
\hline Hours 6 - 11 & 70 & $536 \mathrm{MW}$ & -473 & 0.59 & 3 \\
\hline Hours 12-17 & 96 & $582 \mathrm{MW}$ & -535 & 0.89 & 6 \\
\hline Hours 18- 23 & 119 & $740 \mathrm{MW}$ & -664 & 1.44 & 6 \\
\hline
\end{tabular}

\footnotetext{
${ }^{6}$ For ramps that span two time frames, they are binned by the start time of the ramp
} 

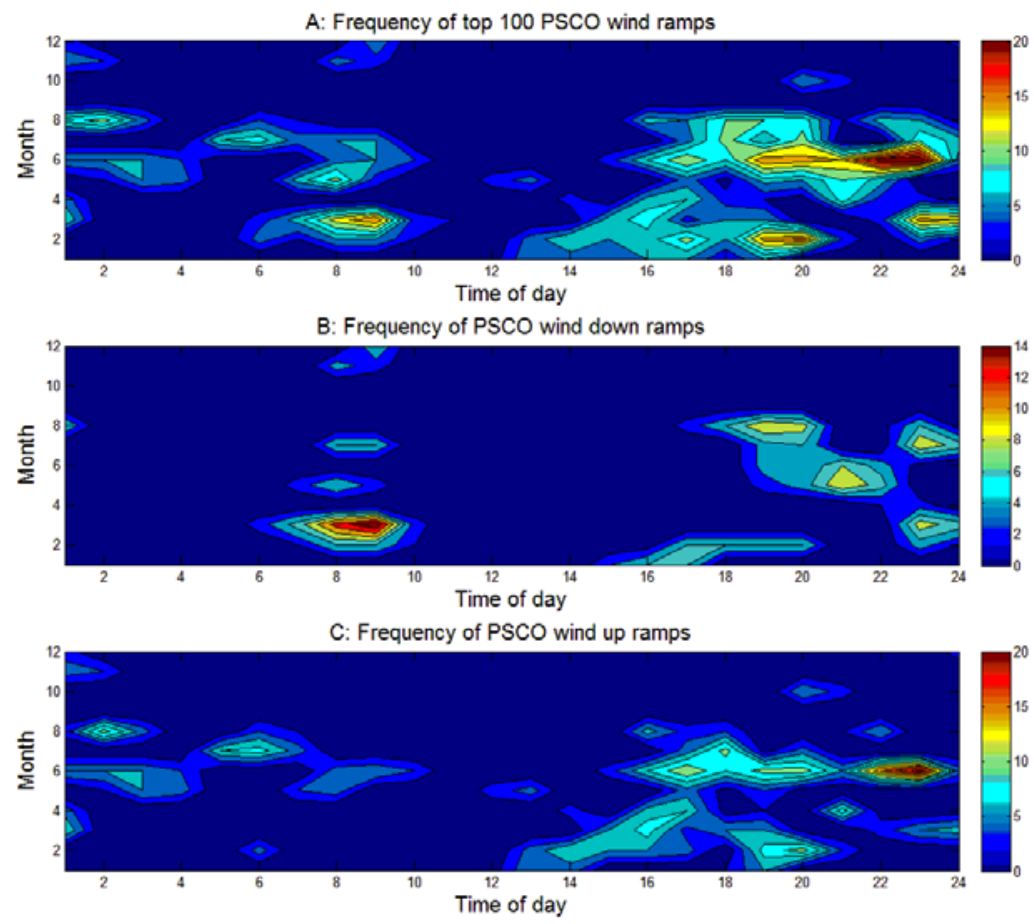

Figure 2 - Contour plot showing PSCO wind ramps by time of day and month

Notice that the time period of hours 18-23 stands out amongst the four periods. This period holds the largest ramps, the most ramps, and is the most volatile according to the number of false ramps. A false ramp is defined as a smaller duration ramp of similar ramp rate that can fool an operator into considering it as the predicted ramp. Since the exact timing of ramp events are so hard to predict, these false ramps become very important. A large wind power down-ramp may have been predicted with confidence that it may start within five hours of some given time. A quick 10-minute down-ramp with similar ramp rate may occur inside that five-hour window, but then stop abruptly. During this false ramp, an operator may turn on a fast-start combustion turbine, but then realizing that it was not needed since the false ramp was short-lived. This can have an impact on reliability and on operating costs. The 1.44 average of false ramps during the evening/night period of hours 18-23 shows that whenever a ramp occurs, there was on average at least one significantly fast but smaller duration ramp in the same direction within five hours of the real ramp. An example of false ramps is shown below in Figure 3 . Lastly, Figure 2 shows that of these ramps occurring in the evening and night time periods, the majority of them occur during the summer months. This is a time of year where load is generally higher due to air-conditioning, so this may add an additional challenge to system operations. There also tends to be a load down-ramp in the later part of this time period (i.e., 22-23) due to declining demand, so when coupled with a wind up-ramp, additional operational challenges can occur. 


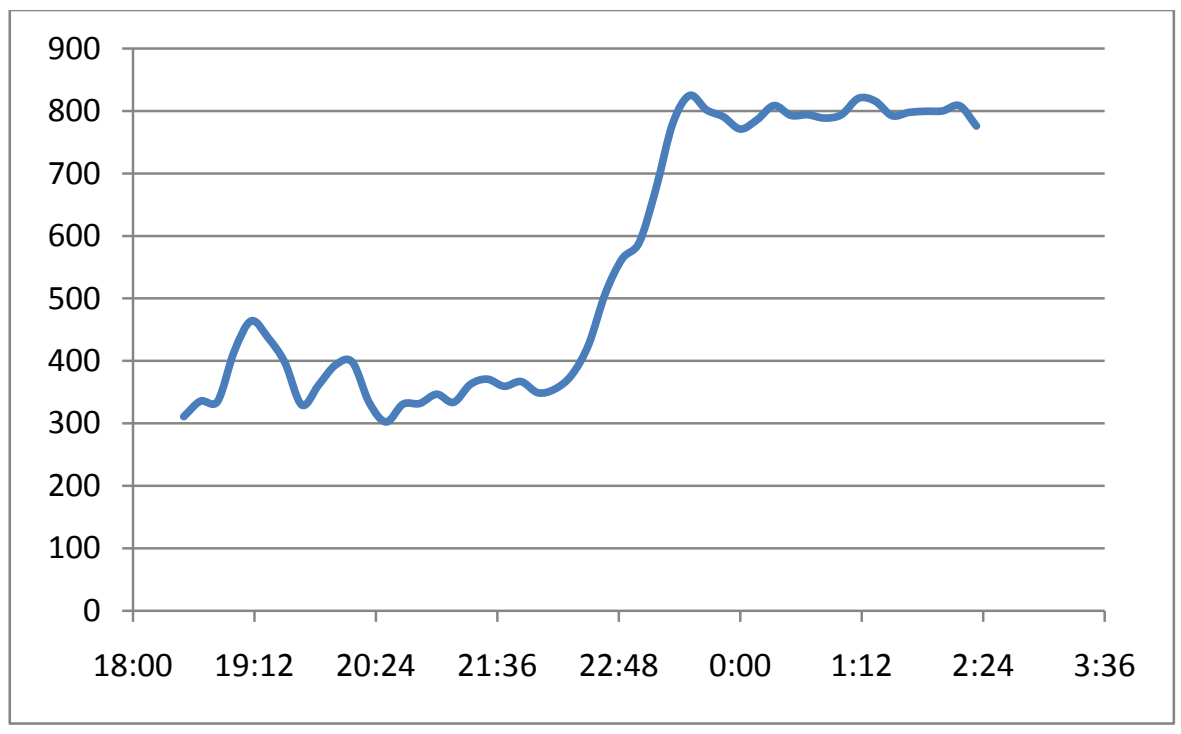

Figure 3 - PSCO wind up-ramp with many false ramps before it

The up-ramp in Figure 3 that started around 21:45 had a series of false ramps preceding it. An operator anticipating the large ramp could easily have been misled into thinking any of the false ramps was the actual forecasted ramp. This is another aspect of a ramp event that is very valuable information to an operator. If the prediction of a ramp event was given with side information that there is anticipated volatility around the ramp, an operator may choose different options than if the ramp was surrounded by less volatility on both sides. A smoother up-ramp is shown below in Figure 4.

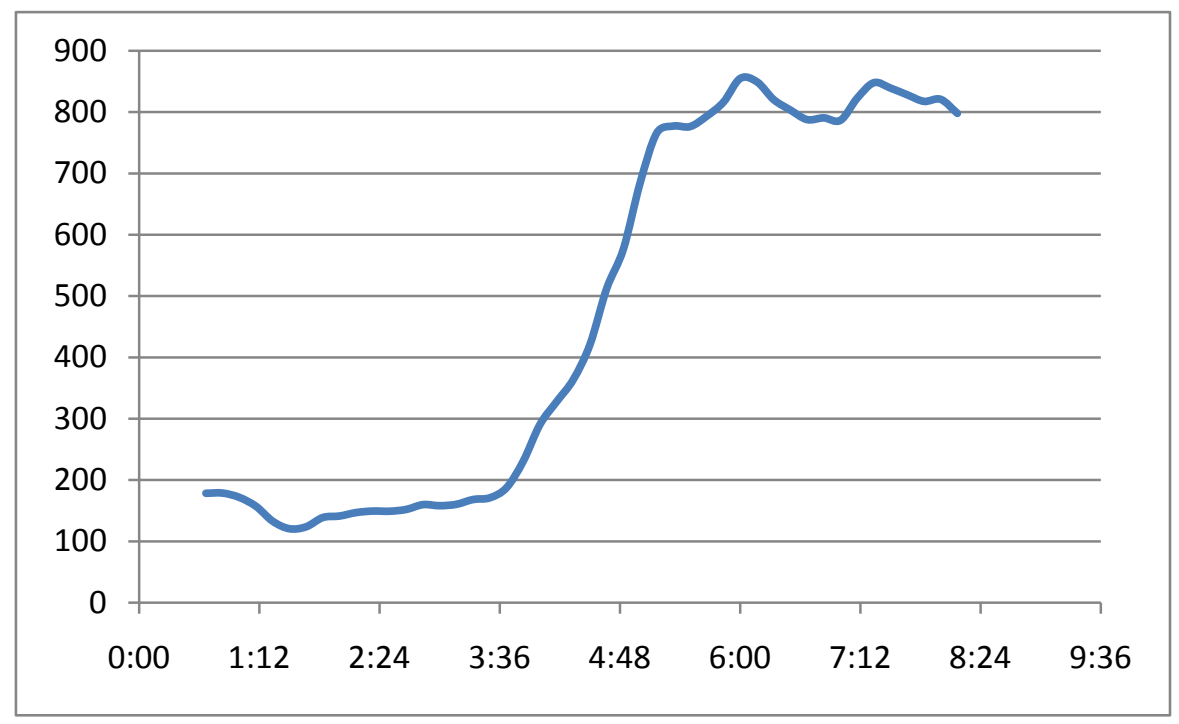

Figure 4 - Large PSCO wind up-ramp with no false ramps before it

As shown in Figure 4, the wind does not fluctuate much before the ramp event. Knowing this ahead of time, an operator would have much more faith that the ramp event starting was indeed a forecasted ramp event. Many of the large up-ramps that occur in PSCO have durations of about 70 minutes. To start adjusting other generation within the first 10 minutes of the ramp is crucial for keeping ACE levels 
down in an economic manner. Because ramp events are currently very difficult to predict with perfect timing, it is often up to the operator to know when a predicted ramp is starting and act accordingly.

One important factor for understanding ramps on a particular system is how they are being caused and what parts of a fleet are contributing. During a system-wide ramp event, the behavior of different wind plants throughout the system can vary significantly. Interestingly, because of the geographical locations of the PSCO wind plants, the wind ramp events in this system generally are caused by the same wind plants each time. The northeast area of PSCO has the majority of the wind capacity and the wind plants are very close in proximity to each other. A large down-ramp and a large up-ramp are shown below in Figure 5 and Figure 6 , respectively. The names of the wind plants are given by their meter-read injection points onto the PSCO system.

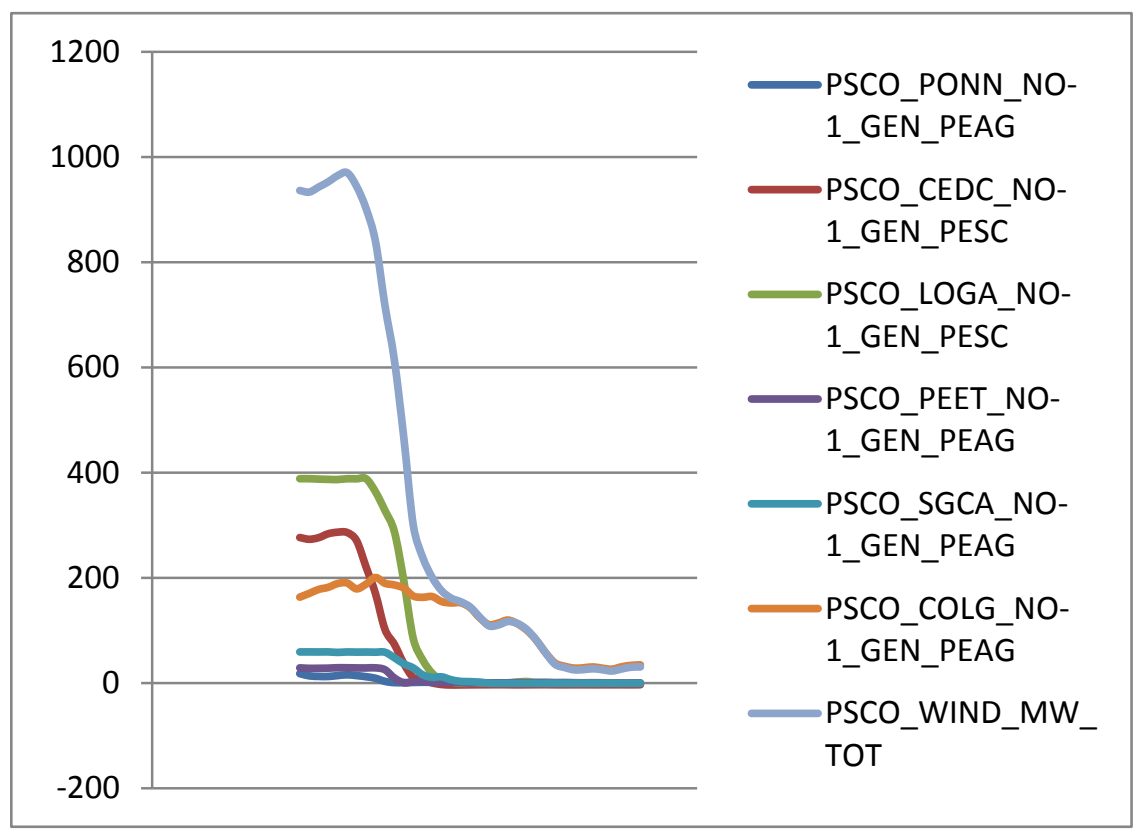

Figure 5 - Contributions from numerous PSCO wind plants during large down-ramp 


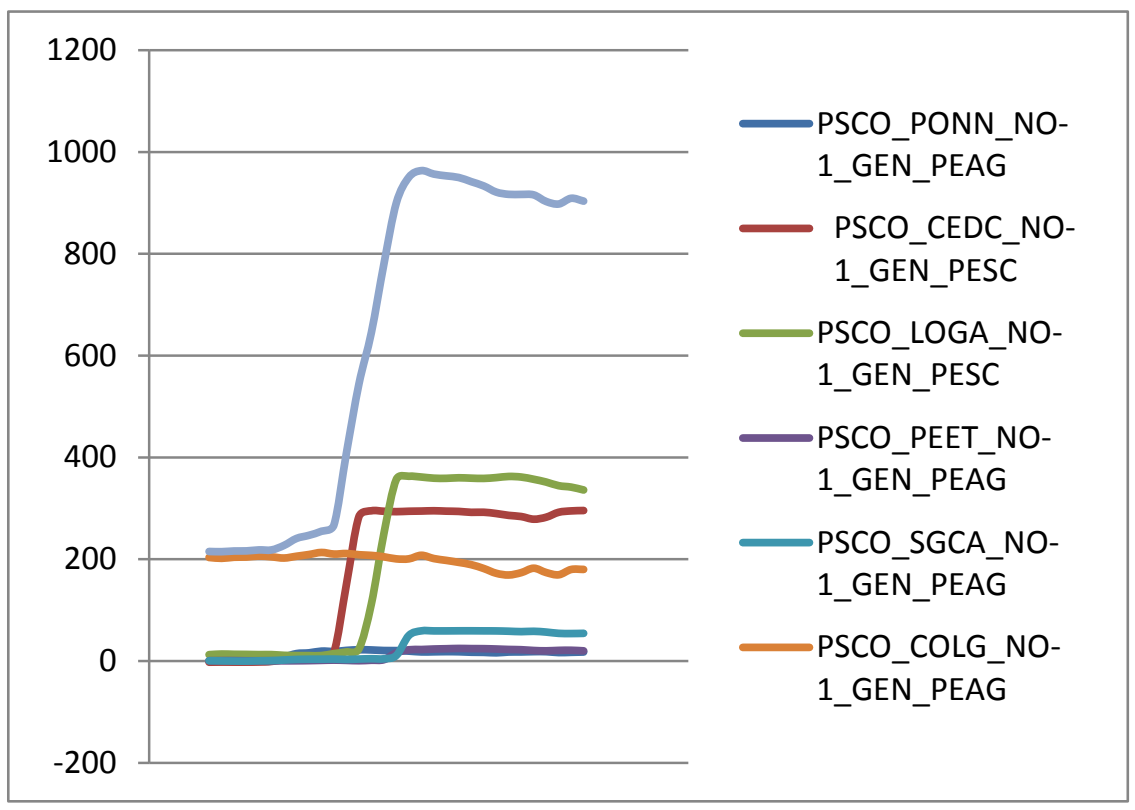

Figure 6 - Contributions from numerous PSCO wind plants during large up-ramp

It is important to know the locations of the plants. CEDC and LOGA are the largest plants on the PSCO system and are located in the northeast corner of Colorado along with PONN, PEET, and SGCA. COLG is located in the southeast corner of the state and over 200 miles away from each of the other connection points. In the northeast, the order of west to east is as follows: PONN, CEDC, PEET, LOGA, and SGCA. In both figures, the movement in power production starts with the western-most area first and moves east. For the up-ramp, this obviously shows an increase in wind coming from the west. For the downramp, Figure 5 shows that either the winds began to taper off west to east or the wind was increasing so much that cut-out levels were reached as it moved across the state towards the east. The latter looks possible given that most of the wind plants are operating at very close to their maximum capacity just prior to the beginning of the ramp.

The behavior of ramp events in PSCO starting from west to east is very typical of the wind regime in this system, but as shown in Figure 7, it is not always the case. This plot shows the two larger plants that contribute the most to PSCO wind ramps. Unlike the last two plots and the more typical behavior of the system, this ramp starts with LOGA ramping up, and is followed shortly after by CEDC ramping up. This describes an increase in wind speed east to west and was seen as more common in certain months of the year. 


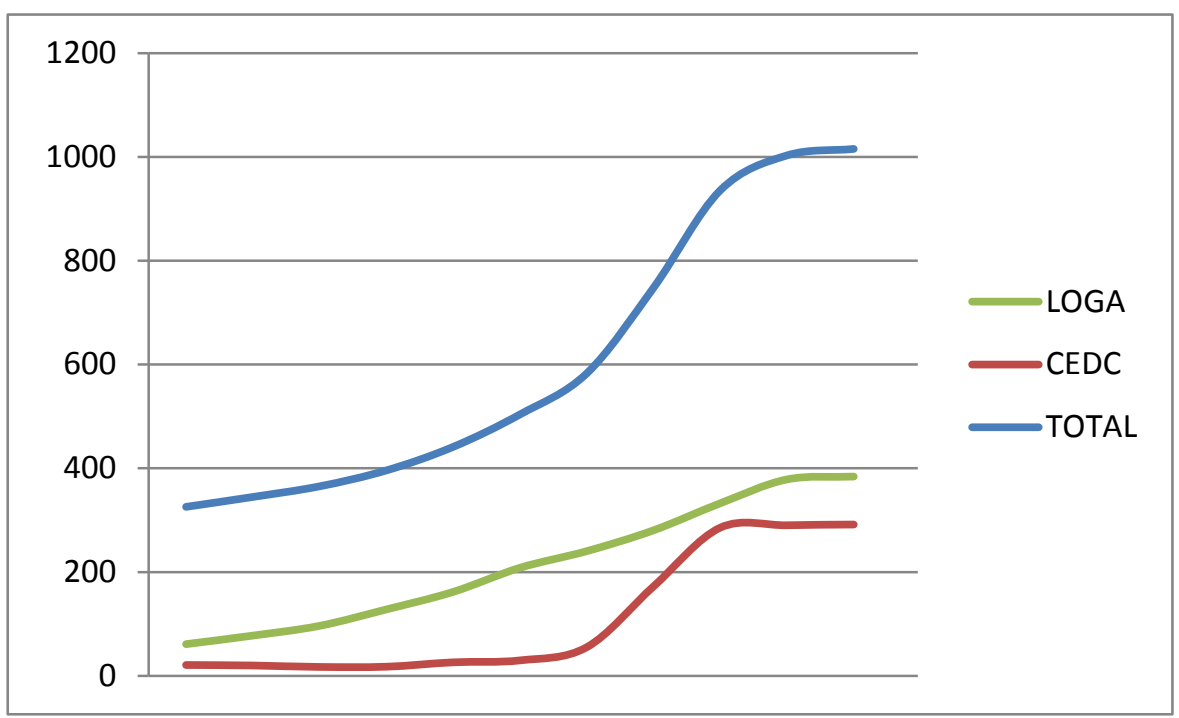

Figure 7 - Up-ramp showing easterly Logan increasing before cedar creek

Table IV shows the number of times where large wind ramps are starting west to east and east to west. ${ }^{7}$ This analysis uses the two larger wind plants in the northeast as a proxy and determines the direction of the ramp by observing which plant contributed to the ramp first. A west to east up-ramp means that the western plant increased in production before the eastern plant and a west to east down-ramp means that the western plant started to decrease its production before the eastern plant. The results show minimal conclusions other than there is a slightly greater number of west to east ramps throughout the year.

Table IV - PSCO ramp directions

\begin{tabular}{|l|l|l|}
\hline & West to East & East to West \\
\hline Total & 47 & 41 \\
\hline Up-ramps & 30 & 28 \\
\hline Down-ramps & 17 & 13 \\
\hline Spring & 14 & 13 \\
\hline Summer & 11 & 12 \\
\hline Fall & 13 & 8 \\
\hline Winter & 9 & 8 \\
\hline
\end{tabular}

The timing of individual wind plants' ramping events was then further compared to the timing of system-wide ramp events for PSCO. First, system-wide wind ramps exceeding $20 \%$ of total capacity of the system were identified and then individual wind plant ramps exceeding $40 \%$ capacity of the wind plant were identified. The starting times of those ramp events were compared using a sub-program. The sub-program assumed that an individual plant was more likely to experience a ramp event of

\footnotetext{
${ }^{7}$ Though useful, this analysis was very sensitive to how thresholds were set up. Both wind plants may be moving in a similar direction, but it is difficult to quantify a threshold on whether the movement is the start of the ramp or not.
} 
corresponding sign (plus or minus) than a ramp event of opposing sign. The sub-program searched all of the PSCO up-ramp starting times and sought to find an individual plant up-ramp start within two hours before or after the system-wide ramp. If no corresponding up-ramp start existed, then the sub-program searched for a down-ramp start within the same four-hour period. Analysis in this manner may tend to over count aligned ramps and under count opposing ramps. Regardless, the methodology was applied equally to all individual plants. The results, summarized in Table V, show that Colorado Green was the least likely to have identified ramp starts that aligned with system-wide ramps with $27 \%$ of up-ramps and $24 \%$ of down-ramps aligning. Logan was the most likely to have aligned ramps with $61 \%$ of upramps and $54 \%$ of down-ramps aligning.

Overall, all wind plants had higher ratios of aligned to opposed wind ramp starts during system-wide down-ramps than up-ramps. This was due to the low numbers of individual power plant up-ramp starts coinciding with system-wide down-ramp starts (Table $\mathrm{V}$, bottom half of column 2 versus the top half). Thus, at least for the ramp starting times, it appears that individual wind plant power profiles are more correlated during down-ramps than up-ramps. In other words, when the wind throughout the system is starting to ramp down, it is unlikely that an individual wind power plant is beginning to ramp up.

Table V - Individual wind plant ramps aligning or opposing system-wide wind ramps

\begin{tabular}{|c|c|c|c|c|c|}
\hline $\begin{array}{l}\text { PSCO } \\
\text { ramping } \\
\text { up vs. }\end{array}$ & $\begin{array}{l}\text { Total aligned } \\
\text { ramp event } \\
\text { starts }\end{array}$ & $\begin{array}{l}\text { Total opposed } \\
\text { ramp event } \\
\text { starts } \\
\end{array}$ & $\begin{array}{l}\% \text { of PSCO up ramps } \\
\text { that had an aligned } \\
\text { (up) ramp at } \\
\text { specified plant }\end{array}$ & $\begin{array}{l}\text { \% of PSCO up ramps } \\
\text { that had an opposed } \\
\text { (down) ramp at } \\
\text { specified plant }\end{array}$ & $\begin{array}{l}\text { Ratio of aligned to } \\
\text { opposed ramp } \\
\text { events }\end{array}$ \\
\hline PEET & 155 & 12 & $53 \%$ & $4 \%$ & 12.9 \\
\hline PONN & 113 & 19 & $39 \%$ & $6 \%$ & 5.9 \\
\hline SGCA & 155 & 16 & $53 \%$ & $5 \%$ & 9.7 \\
\hline COLG & 78 & 15 & $27 \%$ & $5 \%$ & 5.2 \\
\hline CEDC & 164 & 22 & $56 \%$ & $8 \%$ & 7.5 \\
\hline LOGA & 179 & 16 & $61 \%$ & $5 \%$ & 11.2 \\
\hline $\begin{array}{l}\text { PSCO } \\
\text { ramping } \\
\text { down vs. }\end{array}$ & $\begin{array}{l}\text { Total aligned } \\
\text { ramp event } \\
\text { starts } \\
\end{array}$ & $\begin{array}{l}\text { Total opposed } \\
\text { ramp event } \\
\text { starts }\end{array}$ & $\begin{array}{l}\% \text { of PSCO down } \\
\text { ramps that had an } \\
\text { aligned (down) ramp } \\
\text { at specified plant }\end{array}$ & $\begin{array}{l}\% \text { of PSCO down } \\
\text { ramps that had an } \\
\text { opposed (up) ramp } \\
\text { at specified plant } \\
\end{array}$ & $\begin{array}{l}\text { Ratio of aligned to } \\
\text { opposed ramp } \\
\text { events }\end{array}$ \\
\hline PEET & 131 & 10 & $45 \%$ & $3 \%$ & 13.1 \\
\hline PONN & 112 & 4 & $38 \%$ & $1 \%$ & 28.0 \\
\hline SGCA & 129 & 4 & $44 \%$ & $1 \%$ & 32.3 \\
\hline COLG & 69 & 8 & $24 \%$ & $3 \%$ & 8.6 \\
\hline CEDC & 130 & 8 & $44 \%$ & $3 \%$ & 16.3 \\
\hline LOGA & 159 & 7 & $54 \%$ & $2 \%$ & 22.7 \\
\hline
\end{tabular}

\section{B. SPS}

As discussed earlier, SPS has a different geographical structure of its wind plants compared to PSCO. Table VI shows wind ramp statistics for various definitions of wind ramps (contrast with Table II). 
Table VI - SPS wind ramp statistics

\begin{tabular}{|l|l|l|l|l|l|}
\hline SPS Wind 570-600 MW & Total & Up & Down & Average duration & Max duration \\
\hline Ramps over $135 \mathrm{MW}$ in 60 mins (25\%) & 208 & 117 & 91 & $83 \mathrm{~min}$ & $230 \mathrm{~min}$ \\
\hline Ramps over $200 \mathrm{MW}$ in 60 mins (33\%) & 19 & 12 & 7 & $79 \mathrm{~min}$ & $160 \mathrm{~min}$ \\
\hline Ramps over $240 \mathrm{MW}$ in 60 mins (40\%) & 3 & 3 & 0 & $67 \mathrm{~min}$ & $100 \mathrm{~min}$ \\
\hline Ramps over $135 \mathrm{MW}$ in 30 mins & 43 & 24 & 19 & $50 \mathrm{~min}$ & $120 \mathrm{~min}$ \\
\hline
\end{tabular}

For 2008, these definitions of ramps closely resemble those of PSCO in terms of percentage of total wind plant capacity. It is observed that when normalizing the ramp definitions with total installed capacity, that SPS has far less ramping issues related to wind power. For the middle 60-minute definition, corresponding to about 33\% of installed capacity change in 60 minutes, there are about 5 times as many ramps in PSCO as there are in SPS. From an operator's perspective, it is more comforting to know that an up-ramp of $40 \%$ or more may only occur 3 times in one year and that a down-ramp of the same size is extremely rare. Another observation is that the average duration of the ramps in SPS is a bit longer than that of PSCO. This is most likely due to the geographical spread in SPS. Lastly, you can see that there are significantly more up-ramps compared to down-ramps, similar to PSCO.

Table VII shows specific time-of-day statistics of wind ramps in SPS. In this table, false ramps are defined as a 10 -minute ramp of $25 \mathrm{MW}$ or more inside a 5 -hour window. Figure 8 shows ramp statistics by time of day and by month.

Table VII - SPS wind ramp statistics by time of day

\begin{tabular}{|l|l|l|l|l|l|}
\hline $\begin{array}{l}\text { Ramps over 135 } \\
\text { MW in 60 mins }\end{array}$ & Ramps & $\begin{array}{l}\text { Max 60 m } \\
\text { up ramp }\end{array}$ & $\begin{array}{l}\text { Max 60 m } \\
\text { down ramp }\end{array}$ & $\begin{array}{l}\text { Average false ramps (25 } \\
\text { MW in 10 min inside 5- } \\
\text { hour window) }\end{array}$ & $\begin{array}{l}\text { Maximum false ramps } \\
\text { (25 MW in 10 min } \\
\text { inside 5-hour window) }\end{array}$ \\
\hline Hours 0 - 5 & 41 & $229 \mathrm{MW}$ & $-228 \mathrm{MW}$ & 1.54 & 8 \\
\hline Hours 6 - 11 & 43 & $205 \mathrm{MW}$ & $-230 \mathrm{MW}$ & 1 & 7 \\
\hline Hours 12-17 & 54 & $241 \mathrm{MW}$ & $-207 \mathrm{MW}$ & 0.93 & 6 \\
\hline Hours 18 - 23 & 70 & $292 \mathrm{MW}$ & $-206 \mathrm{MW}$ & 1.36 & 6 \\
\hline
\end{tabular}

\footnotetext{
${ }^{8} 50 \%$ of SPS wind ramp definition showed no ramps at all and therefore, $40 \%$ was displayed.
} 

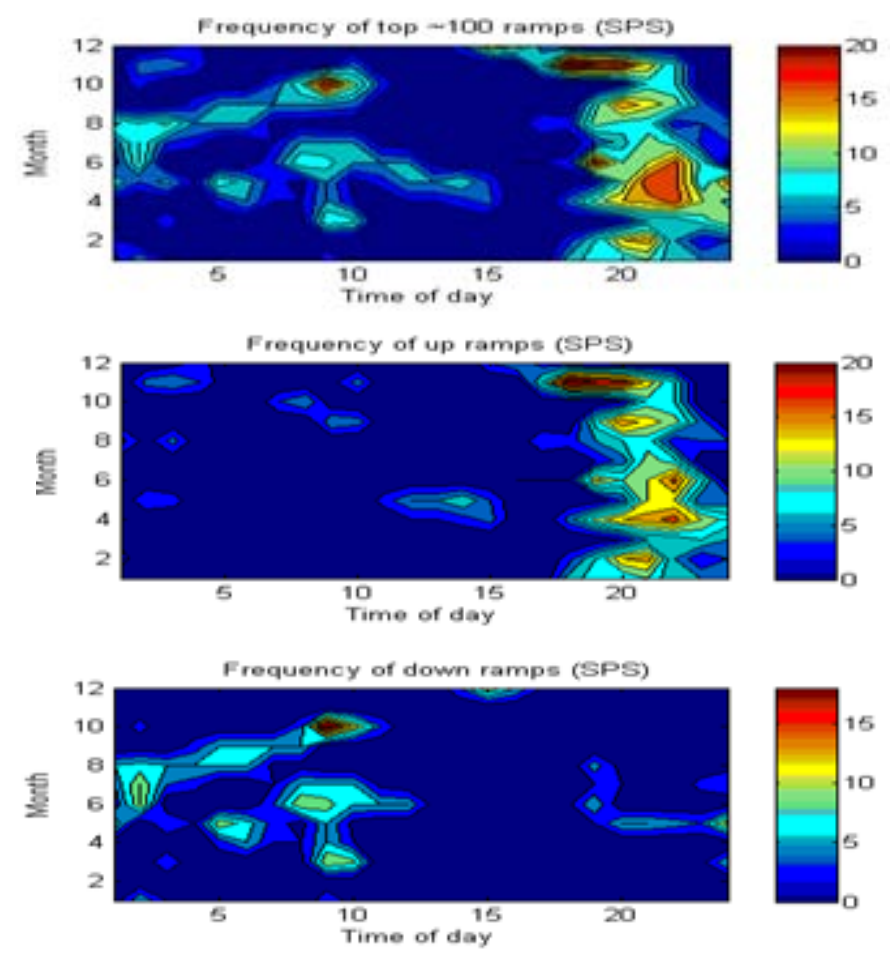

Figure 8 - Contour plot showing SPS wind ramps by time of day and month

These results slightly resemble the PSCO results in that there are a greater number of ramps in the period of hours 18-23 compared to the other time periods. However, the occurrences of false ramps seem to be more consistent between all time periods. Figure 8 shows when up-ramps are occurring compared to down-ramps. It appears that the majority of the ramps occurring during the evening and night period are up-ramps and that most down-ramps occur earlier in the day. This type of correlation between wind ramp direction and time of day was not seen in PSCO.

Figure 9 shows two of the three ramps identified as a $40 \%$ or greater ramp in 60 minutes.

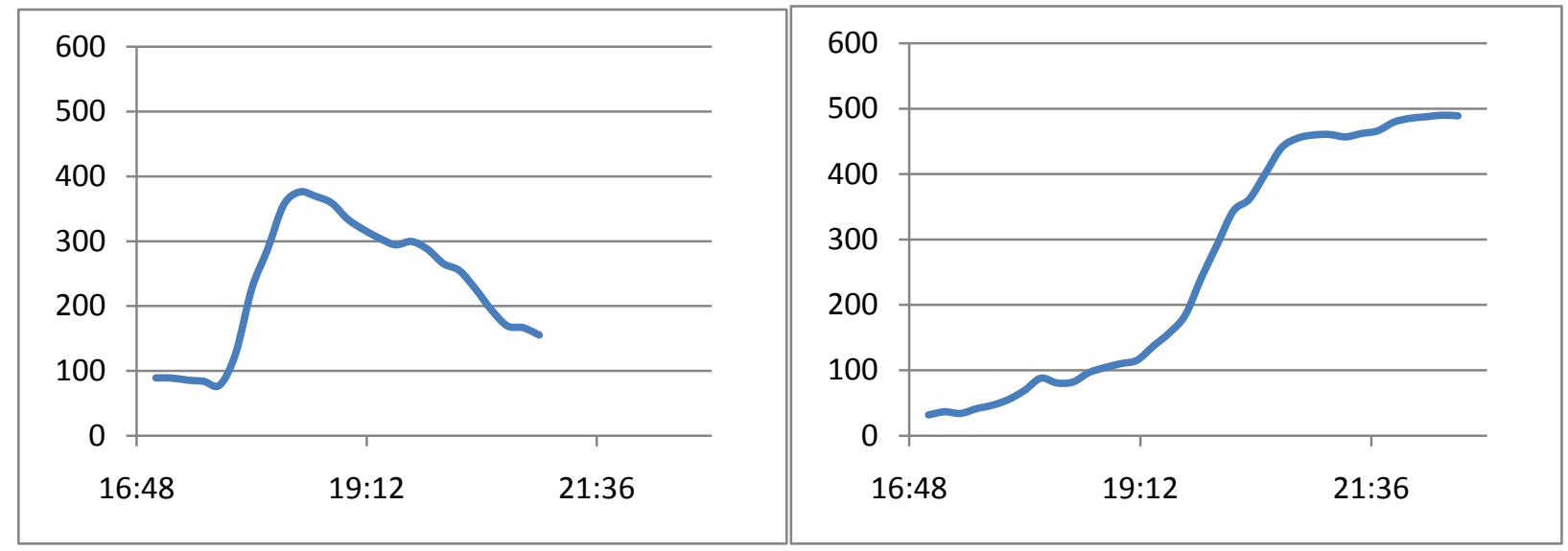

Figure 9 - Two SPS wind ramps 
Figure 9 shows a 50-minute ramp on the left and a 100-minute ramp on the right. The ramp on the left is also followed by a slower down-ramp. Figure 10 and Figure 11 show the contributions from different wind plants for these two wind ramps.

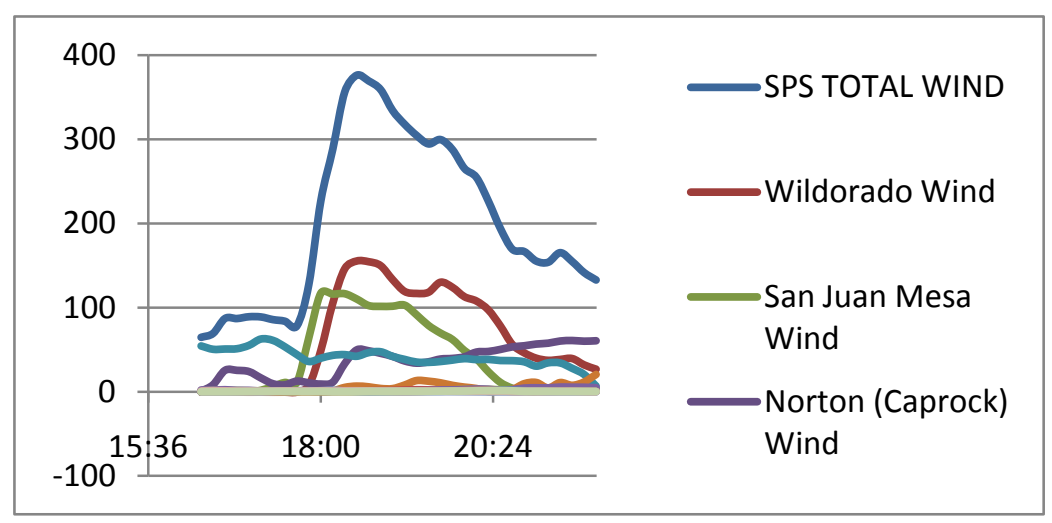

Figure 10 - SPS wind ramp and wind plant contributions

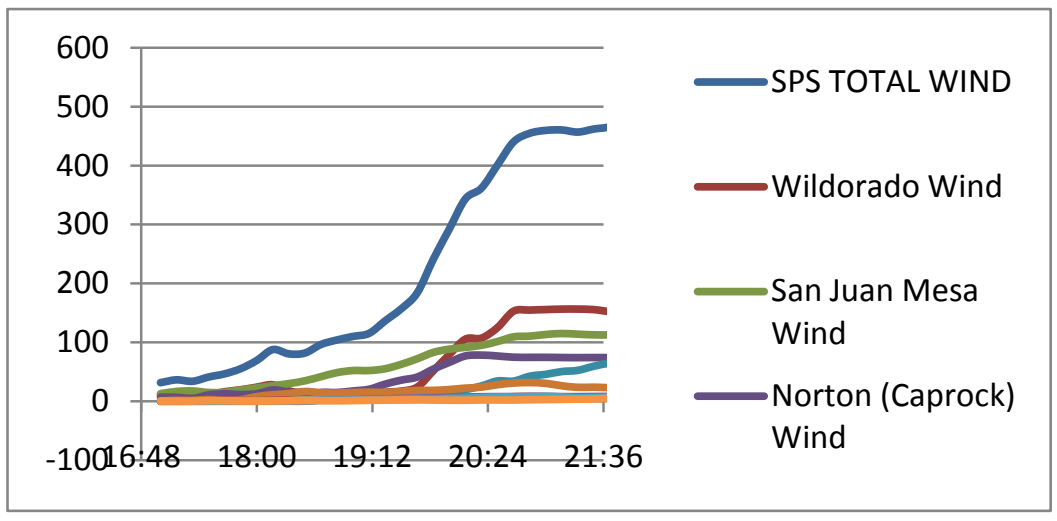

Figure 11 - SPS wind ramp and wind plant contributions

In Figure 10 most wind plants have a rapid increase in power production which makes the ramp more difficult to manage. In Figure 11, many of the plants have a longer duration increase giving the operators more flexibility in what units to adjust or what techniques to use to compensate for the changing wind. In Figure 11, because a down-ramp is immediately following the up-ramp, the operator must be careful about what is done in this situation. Many generators have minimum down-times (times the unit must stay off-line when shut down before being started up again); therefore, another option would have most likely been more practical than turning a unit off. It is possible that the most economic and reliable option in this case may be to curtail the wind during its up-ramp, had the event been perfectly predicted. 


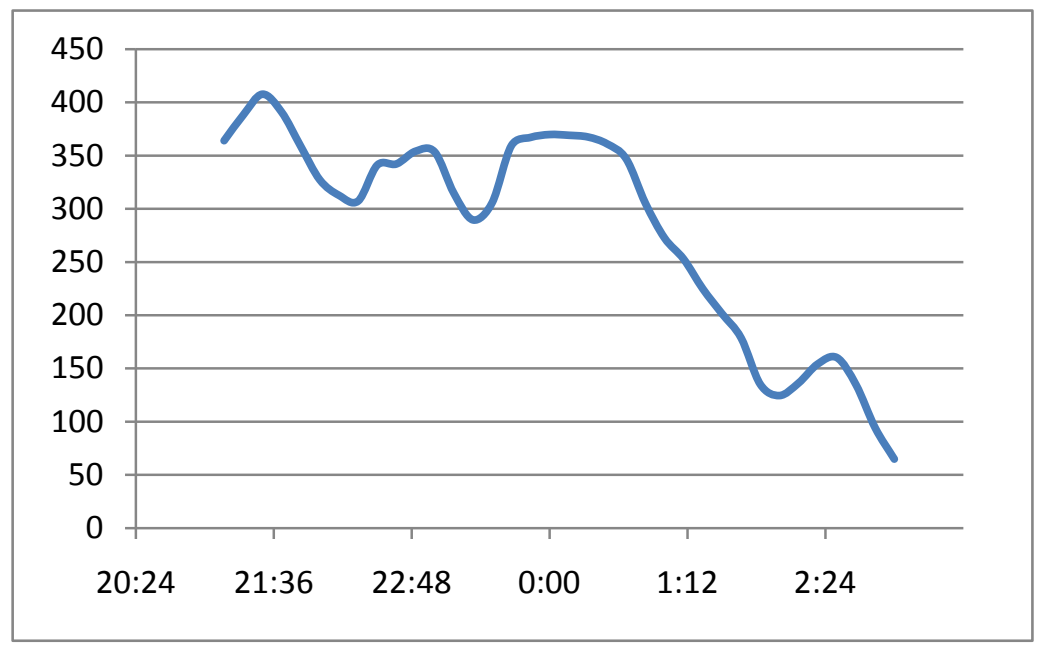

Figure 12 - SPS wind down-ramp with preceding false ramps

Figure 12 shows a highly variable time period where two significant false ramps occurred before the major down-ramp. These are some of the hardest events to react to in that it is never fully known when to ramp units all the way up or turn units on to compensate for the largest predicted ramp. When normalized to each other, there was no significant difference between the average number of false ramps inside the same forecast window between PSCO and SPS.

\section{PSCO and SPS combination}

The team also pursued an analysis of impacts of wind ramps assuming SPS and PSCO were considered as one balancing area. These areas are not geographically connected and are in fact on different sides of the US electrical interconnections. ${ }^{9}$ Therefore, this assessment is an unrealistic scenario but the results of showing what further geographic diversity could bring made it worthwhile. Table VIII shows the ramp statistics for different definitions, still keeping consistent the percentage of installed wind capacity with the last two ramp statistics tables.

\footnotetext{
${ }^{9}$ The eastern interconnection ends just west of the SPS region and PSCO is part of the western interconnection. The two interconnections are only connected via limited DC transmission links so balancing between the two regions would not be a normal scenario.
} 
Table VIII - PSCO and SPS combination wind ramp statistics

\begin{tabular}{|l|l|l|l|l|l|}
\hline Total Wind $1650 \mathrm{MW}$ & Total & Up & Down & Average duration & Max duration \\
\hline $\begin{array}{l}\text { Ramps over } 385 \mathrm{MW}(250+135) \text { in } 60 \\
\text { mins (25\%) }\end{array}$ & 81 & 57 & 24 & $86 \mathrm{~min}$ & $220 \mathrm{~min}$ \\
\hline $\begin{array}{l}\text { Ramps over } 550 \mathrm{MW}(350+200) \text { in } 60 \\
\text { mins (33\%) }\end{array}$ & 11 & 10 & 1 & $86 \mathrm{~min}$ & $140 \mathrm{~min}$ \\
\hline $\begin{array}{l}\text { Ramps over } 740 \mathrm{MW}(500+240) \text { in } 60 \\
\text { mins (45\%) }\end{array}$ & 1 & 1 & 0 & $70 \mathrm{~min}$ & $70 \mathrm{~min}$ \\
\hline Ramps over $385 \mathrm{MW}$ in 30 mins & 17 & 13 & 4 & $52 \mathrm{~min}$ & $100 \mathrm{~min}$ \\
\hline
\end{tabular}

As would be expected, the number of ramps is substantially lowered assuming similar definitions based on percent of nameplate capacity. Combining the two areas result in ramps of $25 \%$ of capacity in 60 minutes about once every 4 or 5 days, whereas PSCO had ramps of almost once per day and SPS more than one every two days for the same percentage. Ramps of over 33\% occurred 11 times and ramps over $50 \%$ occurred once in 2008 . This clearly shows that the spreading of wind plant locations throughout very long distances (i.e., increasing geographic diversity) greatly reduces the per-unit wind ramp events on a combined system. Table IX shows time-of-day statistics for the combined PSCO and SPS wind production. Here, a false ramp is defined as a $65 \mathrm{MW}$ change in 10 minutes within a 5-hour window of a defined ramp. The results look similar to the others, most likely because they are dominated by PSCO events. The maximum ramps are almost identical to the PSCO maximum ramps.

Table IX - PSCO and SPS combination wind ramp statistics by time of day

\begin{tabular}{|l|l|l|l|l|l|}
\hline $\begin{array}{l}\text { Ramps over 385 } \\
\text { MW in 60 mins }\end{array}$ & Ramps & $\begin{array}{l}\text { Max 60 min } \\
\text { up ramp }\end{array}$ & $\begin{array}{l}\text { Max 60 min } \\
\text { down ramp }\end{array}$ & $\begin{array}{l}\text { Average false ramps } \\
\text { (65 MW in 10 min } \\
\text { inside 5-hour window) }\end{array}$ & $\begin{array}{l}\text { Maximum false ramps } \\
\text { (65 MW in 10 min } \\
\text { inside 5-hour window) }\end{array}$ \\
\hline Hours 0 - 5 & 13 & $574 \mathrm{MW}$ & $-456 \mathrm{MW}$ & 0 & 0 \\
\hline Hours 6 - 11 & 16 & $552 \mathrm{MW}$ & $-504 \mathrm{MW}$ & 0.38 & 2 \\
\hline Hours 12 - 17 & 22 & $613 \mathrm{MW}$ & $-546 \mathrm{MW}$ & 0.64 & 3 \\
\hline Hours 18 - 23 & 30 & $746 \mathrm{MW}$ & $-663 \mathrm{MW}$ & 1.03 & 4 \\
\hline
\end{tabular}


One large ramp event stood out in the analysis and is shown in Figure 13. It was also a large ramp event for PSCO. The plot is shown below with both SPS and PSCO wind production contributions.

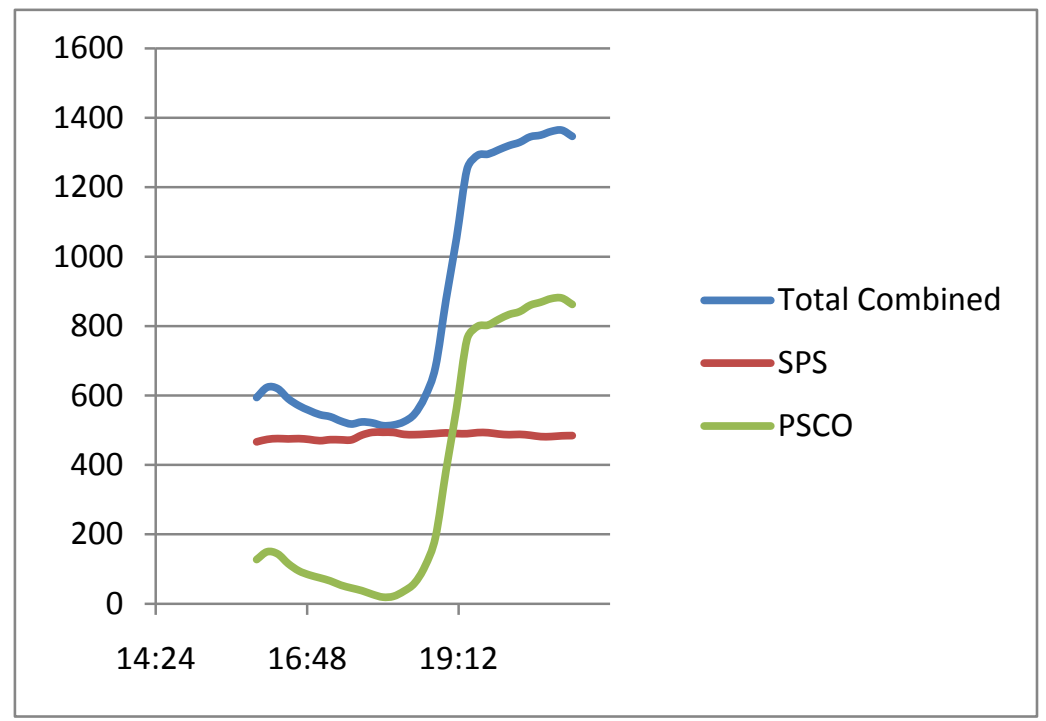

Figure 13 - Wind up-ramp where SPS is constant and PSCO is ramping

This was one of the largest PSCO ramps and was the largest combined ramp as well. The SPS plants stayed relatively constant while the PSCO fleet was increasing greatly. Therefore, the absolute magnitude of the ramp was not affected with the addition of SPS. This behavior was generally the case for most of the large PSCO ramps because SPS production had little to no (to even a beneficial) impact on the combined ramp. Figure 14 shows an up-ramp where both PSCO and SPS were ramping up in production. This type of a combined ramp with both contributions was very rare in the data. The correlation of the two areas during this time frame appear strong and the ramp start and end times appear to be identical between the two distant regions. 


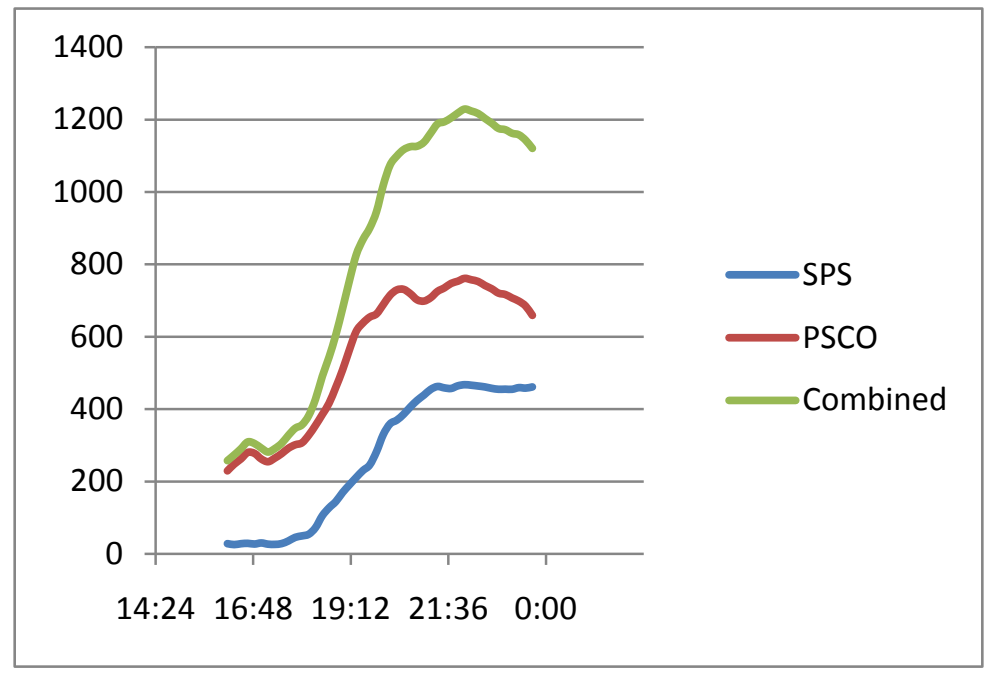

Figure 14 - Combined up-ramp

Further analysis was performed as to how each region was contributing to the top 81 ramps defined in Table VIII. Table $X$ shows the results. PSCO was the major contributor to the majority of wind ramps. A total of $54 \%$ of the ramps had PSCO contributing to over $90 \%$ of the total magnitude of the ramp. SPS contributes less than $30 \%$ of the total ramp magnitude in most cases. Table XI shows the contributions normalized to the regions' size. There are a few more ramps of larger contributions from SPS when they are normalized but it still shows the majority are due to PSCO. However, the 81 ramps were defined from the original data with PSCO dominating the contributions so this is expected. Figure 15 shows histograms of the frequency of percent contribution for the absolute and normalized cases. 
Table X - Frequency of contributions from PSCO and SPS toward combined ramps ${ }^{10,11}$

\begin{tabular}{|r|r|r|r|r|r|}
\hline $\begin{array}{l}\text { PSCO } \\
\text { Bins (\%) }\end{array}$ & Occurrences & \multicolumn{1}{l|}{ Cumulative } & \multicolumn{1}{l|}{$\begin{array}{l}\text { SPS } \\
\text { Bins (\%) }\end{array}$} & Occurrences & Cumulative \\
\hline$<50 \%$ & 1 & 1 & $<0 \%$ & 11 & 11 \\
\hline $55 \%$ & 1 & 2 & $5 \%$ & 17 & 28 \\
\hline $60 \%$ & 2 & 4 & $10 \%$ & 16 & 44 \\
\hline $65 \%$ & 1 & 5 & $15 \%$ & 9 & 53 \\
\hline $70 \%$ & 6 & 11 & $20 \%$ & 9 & 62 \\
\hline $75 \%$ & 2 & 13 & $25 \%$ & 6 & 68 \\
\hline $80 \%$ & 6 & 19 & $30 \%$ & 2 & 70 \\
\hline $85 \%$ & 9 & 28 & $35 \%$ & 6 & 76 \\
\hline $90 \%$ & 9 & 37 & $40 \%$ & 1 & 77 \\
\hline $95 \%$ & 16 & 53 & $45 \%$ & 2 & 79 \\
\hline $100 \%$ & 17 & 70 & $50 \%$ & 1 & 80 \\
\hline$>100 \%$ & 11 & 81 & $>50 \%$ & 1 & 81 \\
\hline
\end{tabular}

Table XI - Frequency of contributions from PSCO and SPS toward combined ramps, normalized to region capacity

\begin{tabular}{|r|r|r|r|r|r|}
\hline \multicolumn{1}{l|}{$\begin{array}{l}\text { PSCO } \\
\text { Bins (\%) }\end{array}$} & Occurrences & \multicolumn{1}{l|}{$\begin{array}{l}\text { CPS } \\
\text { Cumulative }\end{array}$} & $\begin{array}{l}\text { Bins (\%) } \\
\text { Occurrences }\end{array}$ & \multicolumn{1}{l|}{ Cumulative } \\
\hline$<50 \%$ & 4 & 4 & $<0 \%$ & 11 & 11 \\
\hline $55 \%$ & 6 & 10 & $5 \%$ & 13 & 24 \\
\hline $60 \%$ & 3 & 13 & $10 \%$ & 7 & 31 \\
\hline $65 \%$ & 0 & 13 & $15 \%$ & 12 & 43 \\
\hline $70 \%$ & 8 & 21 & $20 \%$ & 6 & 49 \\
\hline $75 \%$ & 6 & 27 & $25 \%$ & 5 & 54 \\
\hline $80 \%$ & 5 & 32 & $30 \%$ & 6 & 60 \\
\hline $85 \%$ & 6 & 38 & $35 \%$ & 8 & 68 \\
\hline $90 \%$ & 12 & 50 & $40 \%$ & 0 & 68 \\
\hline $95 \%$ & 7 & 57 & $45 \%$ & 3 & 71 \\
\hline $100 \%$ & 13 & 70 & $50 \%$ & 6 & 77 \\
\hline$>100 \%$ & 6 & 81 & $>50 \%$ & 4 & 81 \\
\hline
\end{tabular}

\footnotetext{
${ }^{10}$ A contribution of greater than $100 \%$ means that the regions ramp was larger than the combination ramp, and the other region must have been opposing the combination ramp. The other region would have a negative contribution.

${ }^{11} 55 \%$ means between 50 and $55 \%$. Each percentage represents less than or equal to that percentage and greater than the prior percentage.
} 


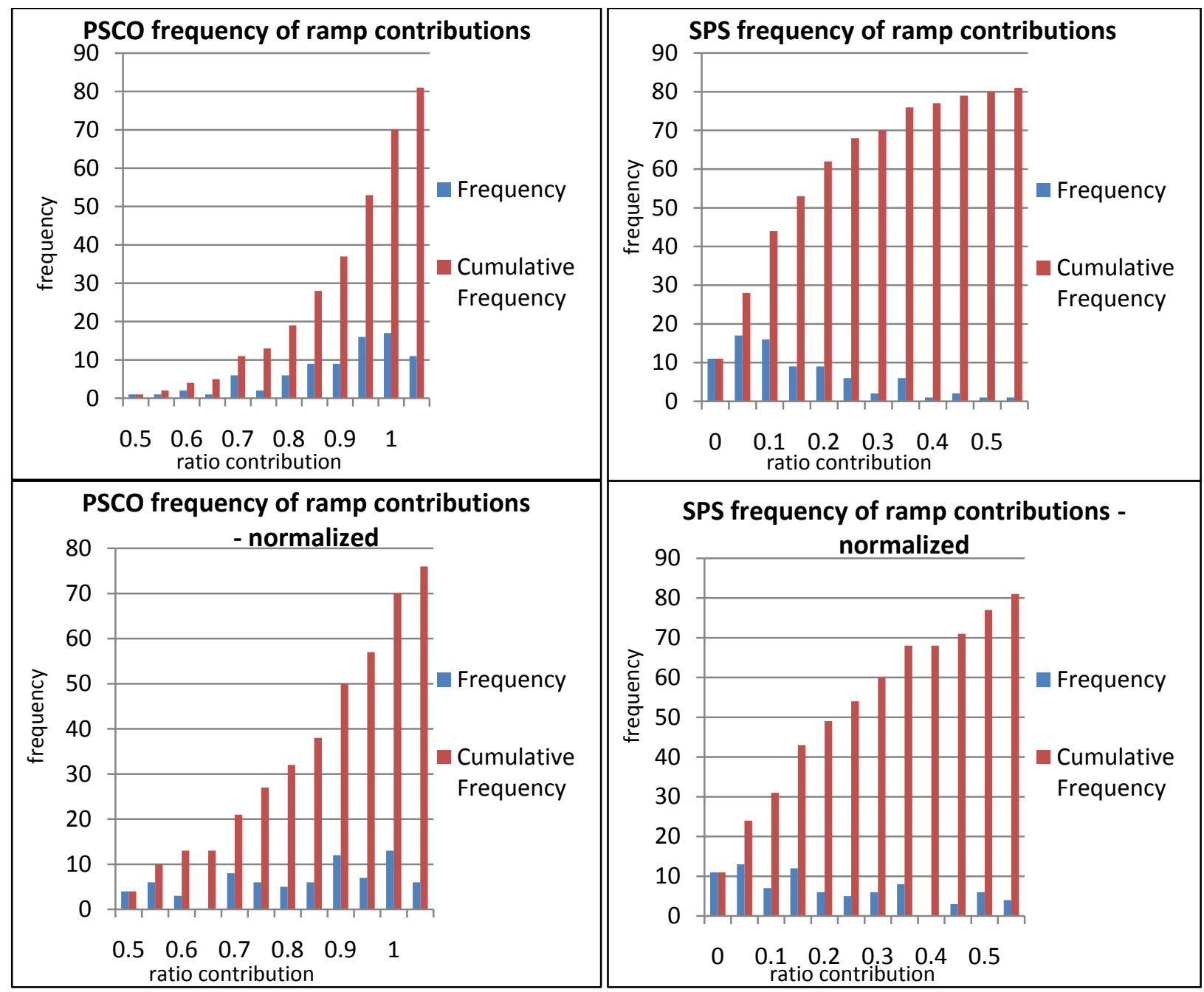

Figure 15 - Frequency of ramp contributions to combined PSCO and SPS ramps

\section{Net Load Ramps}

In reality, operators are responsible for balancing the generation and load together, not independently. Wind up-ramps that occur at the same time as load up-ramps are not of concern to an operator. Wind down-ramps that happen at the same time as load up-ramps, however, can exacerbate the ramping issue of one or the other by itself. The following analysis is of net load ramps. Net load ramps are the total load minus total wind production that is ramping in either direction. Net load ramps are what an operator would need for its conventional generation fleet or other sources of flexibility ${ }^{12}$ to follow.

\section{A. $\mathrm{PSCO}$}

Table XII shows load and net load ramp statistics for PSCO.

\footnotetext{
${ }^{12}$ Other sources of flexibility can include demand response, energy storage, or in some cases, curtailment of wind generation.
} 
Table XII - Load and net load ramp statistics for PSCO

\begin{tabular}{|l|l|l|l|l|l|l|}
\hline \multicolumn{7}{|l|}{ Load Ramps } \\
\hline Peak demand = $6800 \mathrm{MW}$ & Total & Up & Down & $\begin{array}{l}\text { Average } \\
\text { duration }\end{array}$ & Max duration \\
\hline Load ramps over $500 \mathrm{MW}$ in 60 mins & 396 & 214 & 182 & 85 min & 310 min \\
\hline Load ramps over $600 \mathrm{MW}$ in 60 mins & 104 & 52 & 52 & 107 min & 310 min \\
\hline Load ramps over $750 \mathrm{MW}$ in 60 mins & 8 & 6 & 2 & 93 min & 140 min \\
\hline Peak demand = $6800 \mathrm{MW}$ & \multicolumn{2}{|c|}{ Net Load Ramps } & & & \\
\hline Wind capacity = $1060 \mathrm{MW}$ & Total & Up & Down & Average & Max duration \\
\hline Net load ramps over $500 \mathrm{MW}$ in 60 mins & 503 & 254 & 249 & 86 min & 340 min \\
\hline Net load ramps over $600 \mathrm{MW}$ in 60 mins & 205 & 94 & 111 & 97 min & 310 min \\
\hline
\end{tabular}

This table shows the impacts that $1 \mathrm{GW}$ of concentrated wind plant additions have on the ramping characteristics of the PSCO system. Ramp definitions used are 500, 600, and $750 \mathrm{MW}$ in a 1-hour period. Each of these different definitions is impacted differently with wind added on to the system. Larger ramp thresholds have increasingly higher numbers when wind is added to the system. The number of ramps increases by $25 \%, 100 \%$, and well over $300 \%$ for the 500,600 , and $750 \mathrm{MW}$ cases, respectively. Each of these different categories may have different mitigation strategies (if not inclusive as they are displayed here), and therefore, the impact on how often each is occurring is important. Given that the absolute number of ramp occurrences increases are about the same for the $500 \mathrm{MW}$ and $600 \mathrm{MW}$ cases shows that there are very few increases in ramps between $500 \mathrm{MW}$ and $600 \mathrm{MW}$ in 60 minutes when wind is added to the system. These types of ramps are probably characteristic of a morning ramp-up or an evening ramp-down, and operators are used to dealing with these ramps. Having double the number of ramps over $600 \mathrm{MW}$ and over four times as many ramps over $650 \mathrm{MW}$ is a substantial impact, 
however. For ramps of these magnitudes, new operational practices may need to be developed to keep the same reliability levels and costs down. The change in distribution of up- and down-ramps is also interesting. For the major ramps that are greater than $750 \mathrm{MW}$ in magnitude, the majority of the increases are in down-ramps, signifying that the wind up-ramps are mostly contributing to this increase. Another impact, as shown in Table XIII, is the change and possibly lessened predictability of the timing of these ramps.

Table XIII - Load and net load ramp statistics for PSCO by time of day

\begin{tabular}{|c|c|c|c|c|c|}
\hline \multicolumn{6}{|c|}{ Load Ramps } \\
\hline $\begin{array}{l}\text { Load ramps over } 600 \\
\text { MW in } 60 \text { mins }\end{array}$ & Ramps & $\begin{array}{l}\text { Max } 60 \mathrm{~min} \\
\text { up ramp }\end{array}$ & $\begin{array}{l}\text { Max } 60 \mathrm{~min} \\
\text { down ramp }\end{array}$ & $\begin{array}{l}\text { Average false } \\
\text { ramps }\end{array}$ & $\begin{array}{l}\text { Maximum false } \\
\text { ramps }\end{array}$ \\
\hline Hours 0 - 5 & 11 & $527 \mathrm{MW}$ & $-653 \mathrm{MW}$ & 1.27 & 4 \\
\hline Hours 6 - 11 & 9 & $692 \mathrm{MW}$ & $-536 \mathrm{MW}$ & 3 & 4 \\
\hline Hours 12 - 17 & 32 & $786 \mathrm{MW}$ & $-495 \mathrm{MW}$ & 0.53 & 3 \\
\hline Hours 18 - 23 & 52 & $611 \mathrm{MW}$ & $-801 \mathrm{MW}$ & 3.12 & 8 \\
\hline \multicolumn{6}{|c|}{ Net Load Ramps } \\
\hline $\begin{array}{l}\text { Net load ramps over } \\
600 \mathrm{MW} \text { in } 60 \text { mins }\end{array}$ & Ramps & $\begin{array}{l}\text { Max } 60 \mathrm{~min} \\
\text { up ramp }\end{array}$ & $\begin{array}{l}\text { Max } 60 \mathrm{~min} \\
\text { down ramp }\end{array}$ & $\begin{array}{l}\text { Average false } \\
\text { Ramps }\end{array}$ & $\begin{array}{l}\text { Maximum false } \\
\text { ramps }\end{array}$ \\
\hline Hours 0 - 5 & 29 & $683 \mathrm{MW}$ & $-1066 \mathrm{MW}$ & 1.28 & 4 \\
\hline Hours 6 - 11 & 31 & $921 \mathrm{MW}$ & $-571 M W$ & 3.32 & 7 \\
\hline Hours 12 - 17 & 38 & $837 \mathrm{MW}$ & $-671 \mathrm{MW}$ & 1.13 & 5 \\
\hline Hours 18 - 23 & 107 & $740 \mathrm{MW}$ & $-1048 \mathrm{MW}$ & 3.33 & 9 \\
\hline
\end{tabular}




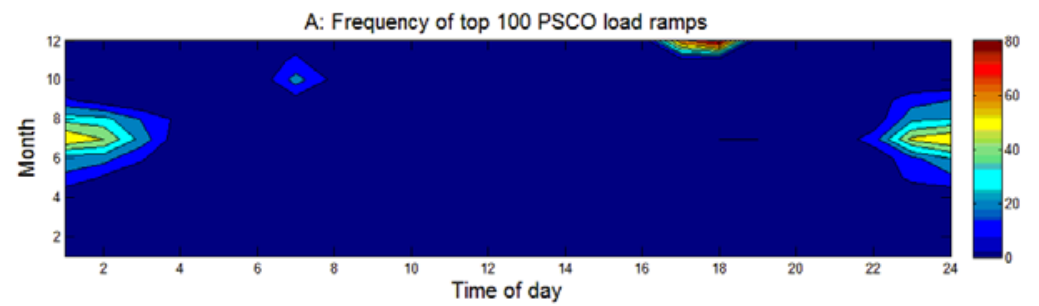

B: Frequency of PSCO load down ramps

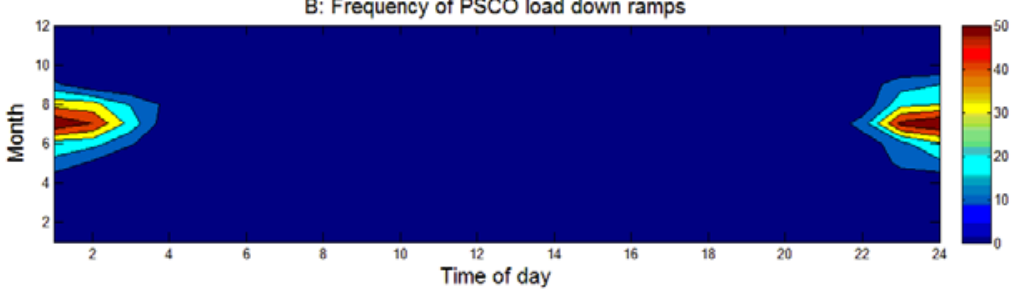

C: Frequency of PSCO load up ramps

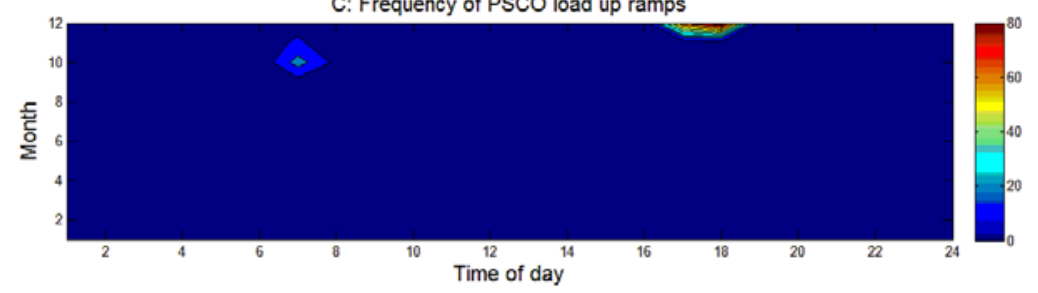

Figure 16 - Contour plot showing PSCO load ramps by time of day and month

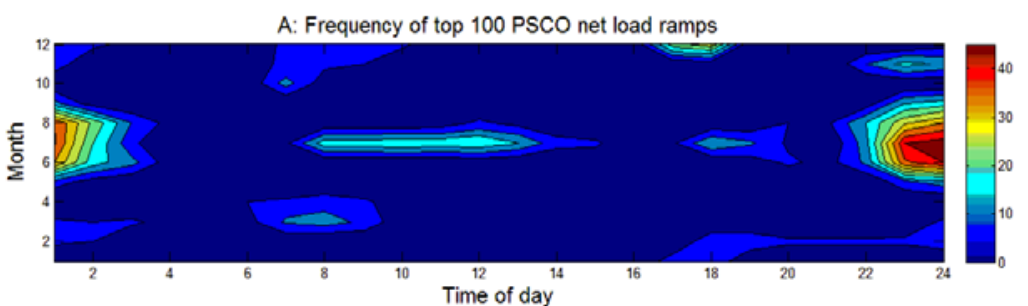

B: Frequency of PSCO net load down ramps

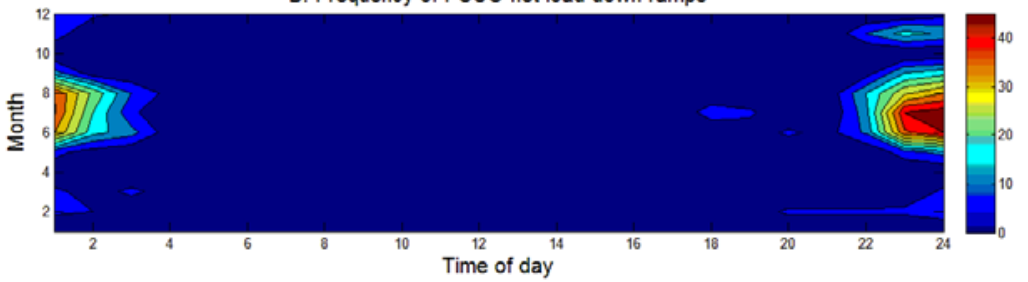

C: Frequency of PSCO net load up ramps

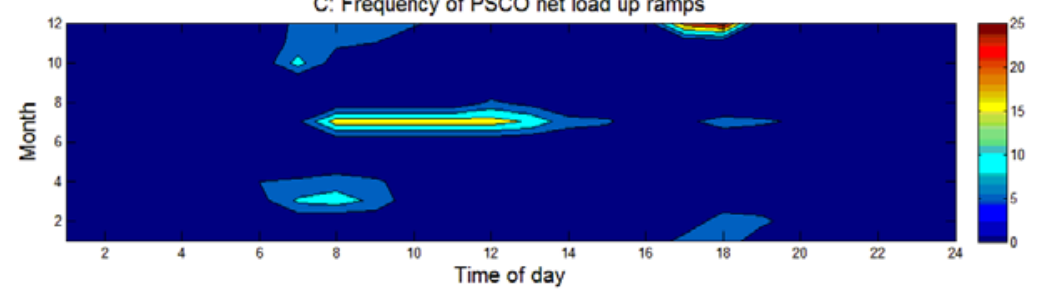

Figure 17 - Contour plot showing PSCO net load ramps by time of day and month 
Figure 16 and Figure 17 show the differences in the timing of significant ramps with added wind in PSCO. Note that Figure 17 uses a different definition to maintain the top 100 criteria. In general, these figures, as well as Table XIII, show that adding the wind to the load will present the morning ramps as more significant, especially during summer months. These are all net load up-ramps and are being amplified with down-ramps of wind. Table XIII shows that the impacts of evening and night time ramps are probably the most severe with the added wind production. The maximum down-ramp has increased by over $250 \mathrm{MW}$ and the number of ramps during this period more than doubled.

\section{B. SPS}

Table XIV shows the total net load ramp statistics for SPS. As a fraction of peak demand, the $375 \mathrm{MW}$ ramp definition is most closely proportional to the $500 \mathrm{MW}$ definition of PSCO in Table XII. The $250 \mathrm{MW}$ ramp definition is lower but was shown to provide additional information.

Table XIV - Net load ramp statistics for SPS

\begin{tabular}{|c|c|c|c|c|c|}
\hline $\begin{array}{l}\text { Peak demand }=5500 \mathrm{MW} \\
\text { Wind capacity }=\sim 570 \mathrm{MW}\end{array}$ & Total & Up & Down & $\begin{array}{l}\text { Average } \\
\text { duration }\end{array}$ & Max duration \\
\hline Ramps over $250 \mathrm{MW}$ in 60 mins & 207 & 97 & 110 & $175 \mathrm{~min}$ & $550 \min$ \\
\hline Ramps over $375 \mathrm{MW}$ in 60 mins & 9 & 3 & 6 & $152 \mathrm{~min}$ & $280 \min$ \\
\hline
\end{tabular}

Any stricter definitions on this table would have resulted in very few or zero ramps, and were taken out of the analysis. One observation from this table is that the ramps of SPS net load were of much longer duration than that of PSCO. Even with less stringent ramp definitions, average durations of ramps were approaching three hours. Longer duration ramps are more manageable operationally than shorter duration ramps of the same magnitude. Table XV shows different ramp statistics by time of day for SPS net load. 
Table XV - Net load ramp statistics for SPS by time of day

\begin{tabular}{|l|l|l|l|l|l|}
\hline $\begin{array}{l}\text { Ramps over 250 MW in } \\
60 \text { mins }\end{array}$ & Ramps & $\begin{array}{l}\text { Max } 60 \mathrm{~min} \\
\text { up ramp }\end{array}$ & $\begin{array}{l}\text { Max } 60 \mathrm{~min} \\
\text { down ramp }\end{array}$ & $\begin{array}{l}\text { Average false } \\
\text { ramps (40 } \\
\text { MW, 10 min) }\end{array}$ & $\begin{array}{l}\text { Maximum false } \\
\text { Ramps (40 MW, } \\
10 \mathrm{~min})\end{array}$ \\
\hline Hours 0 - 5 & 55 & $387 \mathrm{MW}$ & $-323 \mathrm{MW}$ & 0.56 & 9 \\
\hline Hours 6 - 11 & 31 & $448 \mathrm{MW}$ & $-245 \mathrm{MW}$ & 0.77 & 5 \\
\hline Hours 12-17 & 25 & $390 \mathrm{MW}$ & $-308 \mathrm{MW}$ & 0.68 & 4 \\
\hline Hours 18 - 23 & 96 & $274 \mathrm{MW}$ & $-434 \mathrm{MW}$ & 2.35 & 12 \\
\hline
\end{tabular}
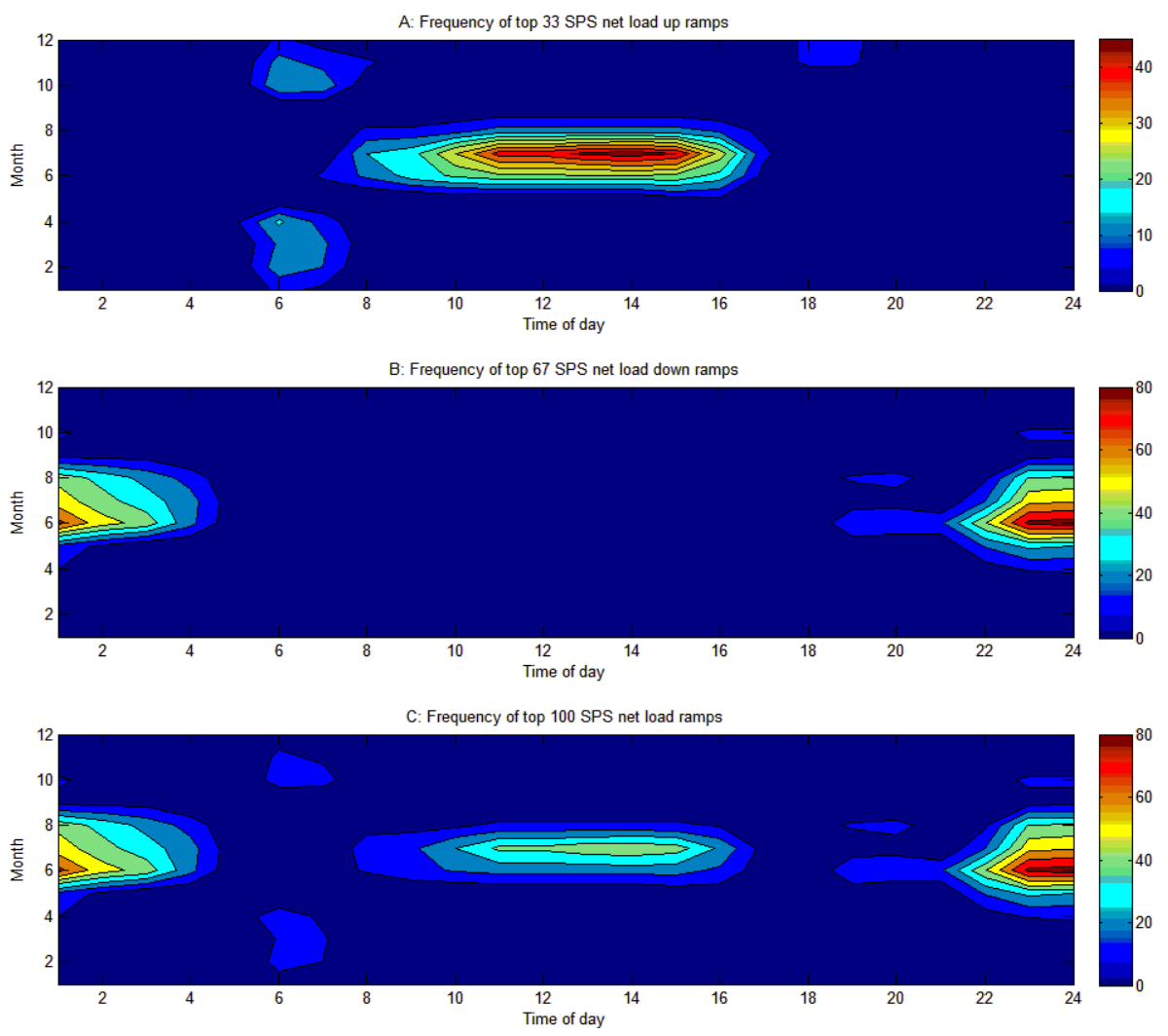

Figure 18 - SPS net load ramp statistics by time of day and month 
The most significant period appears to be the evening period of hours 18 through 23 . Of the 96 ramp periods identified in this period, 95 of them were down-ramps, the typical expectation of load behavior during this period. In fact, as seen in Figure 18, the ramps are more prevalent during the most typical load ramp periods; up-ramps in the summer morning and early afternoon, and down-ramps in the late night and early morning in the summer. Comparing Figures 17 and 18, the temporal characteristics of net load down-ramps for SPS are very similar to PSCO. However, the temporal characteristics of net load up-ramps differ with more evening up-ramps in PSCO during the winter months indicative of heating demands and more summer daytime up-ramps in SPS indicative of cooling demands. These contour plots look similar to the contour plots of the load without wind. This indicates that at current wind penetration levels, addition of wind does not significantly alter the timing of ramping events even though the addition of wind increases variability.

A correlation between the load and the wind in SPS for 10-minute changes was very weak. Further analysis was done to observe contributions during the top ramp periods. Table XVI shows the number of times both wind and load contributed to net load ramps in terms of percentages. In 87 out of 100 ramps, wind contributed less than $50 \%$ to the total net load ramp.

Table XVI - Load and wind contributions to top 100 net load ramps in SPS ${ }^{13,14}$

\begin{tabular}{|r|r|r|r|r|r|}
\hline \multicolumn{1}{l|}{ Load } & Occurrences & Cumulative & lind & Occurrences & Cumulative \\
\hline$<0 \%$ & 0 & 0 & $<0 \%$ & 4 & 4 \\
\hline $10 \%$ & 0 & 0 & $10 \%$ & 16 & 20 \\
\hline $20 \%$ & 0 & 0 & $20 \%$ & 23 & 43 \\
\hline $30 \%$ & 1 & 1 & $30 \%$ & 27 & 70 \\
\hline $40 \%$ & 7 & 8 & $40 \%$ & 10 & 80 \\
\hline $50 \%$ & 5 & 13 & $50 \%$ & 7 & 87 \\
\hline $60 \%$ & 7 & 20 & $60 \%$ & 5 & 92 \\
\hline $70 \%$ & 10 & 30 & $70 \%$ & 7 & 99 \\
\hline $80 \%$ & 27 & 57 & $80 \%$ & 1 & 100 \\
\hline $90 \%$ & 23 & 80 & $90 \%$ & 0 & 100 \\
\hline $100 \%$ & 16 & 96 & $100 \%$ & 0 & 100 \\
\hline$>100 \%$ & 4 & 100 & $>100 \%$ & 0 & 100 \\
\hline
\end{tabular}

\section{Characteristics and Correlation of Wind Plants}

Since wind power is being driven by wind speed that can travel vast distances from wind plant to wind plant, it is important to quantify the correlation between wind plants and times when producing wind

\footnotetext{
${ }^{13}$ A contribution of greater than $100 \%$ means that the wind or load ramp was larger than the net load ramp, and the other contributor (wind or load) must have been opposing the net load ramp. The opposing contributor would have a negative contribution.

${ }^{14} 10 \%$ means between 0 and $10 \%$. Each percentage represents less than or equal to that percentage and greater than the prior percentage.
} 
power production forecasts. Generally, the closer in distance two wind plants are to one another, the more correlated their output will be. Terrain features can also impact the correlation between wind plants. A wind plant may also have a high correlation with the output of a distant wind plant at several time periods ahead or behind. Additionally, correlations may have certain seasonal or hourly characteristics or unique characteristics during ramp periods or non-ramp periods. Knowing correlation of one wind plant from another can assist in the forecasting of ramps when they start to occur.

\section{A. $\mathrm{PSCO}$}

The correlations between individual wind power plants within PSCO were tallied and compared during all times and during times that were identified as up-ramps, down-ramps, and all ramp events collectively, for the top 100 ramps of 2008. These results are presented in Figure 19. For ramp periods and all times, Colorado Green was the least correlated with other wind power plants. However, COLG appeared to be better correlated during down-ramp events than during all times. Other trends also appeared to be sensitive to the direction of the ramp event. For example, CEDC is less correlated with SGCA and PEET during down-ramps than during up-ramps or for all times.
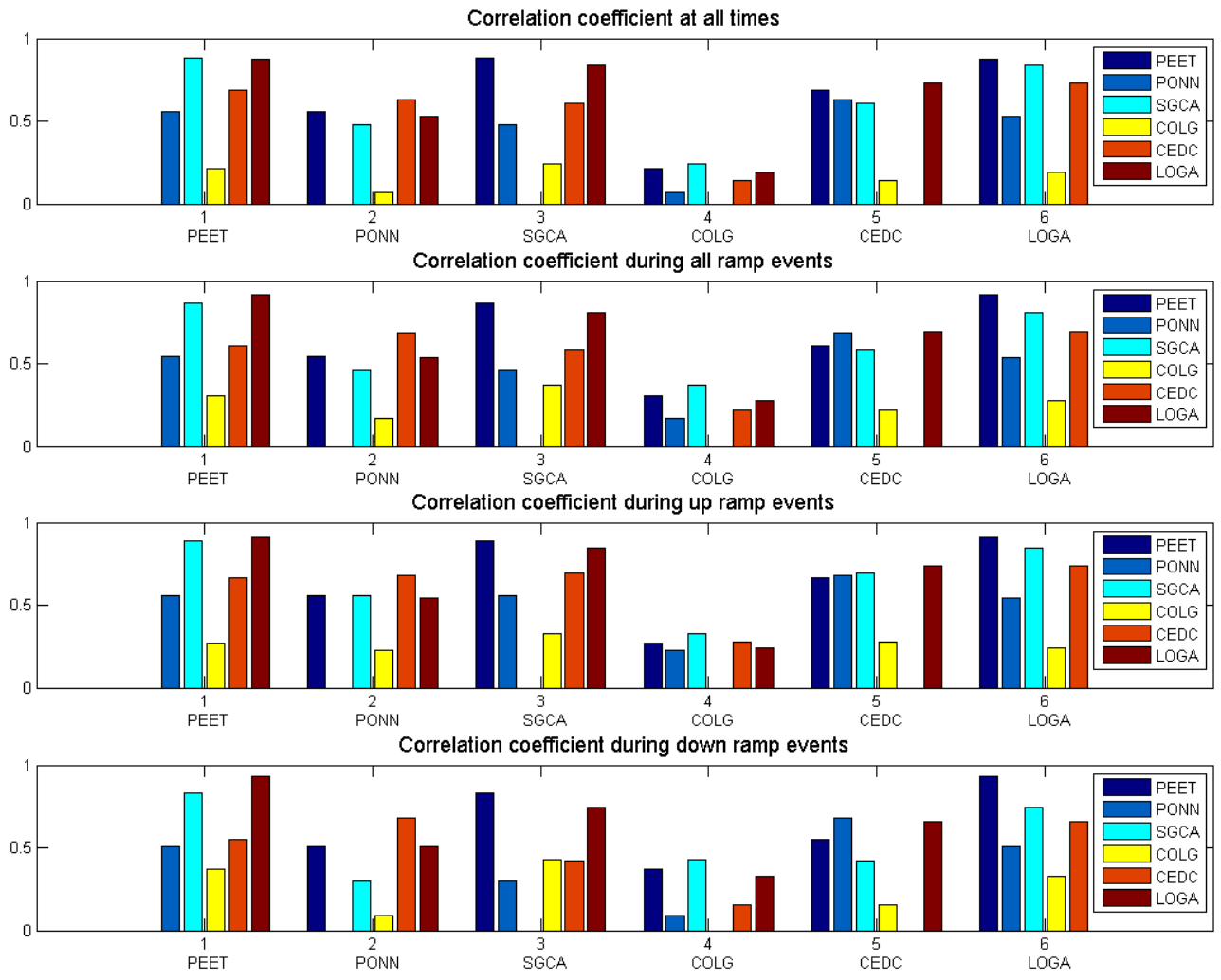

Figure 19 - Correlations between PSCO wind power plants during ramp periods and all times

COLG and PONN, based on both the assessment of ramp starting times (see Table $V$ above) and correlations with other wind power plants during ramp events, contribute the least to system-wide ramp events. Wind power plants contribute differently to the total power output of wind in a particular 
area for a variety of reasons: local topography, size and age of machines, the number of machines, the distance between turbines within a wind power plant and the distance between wind power plants. The distance between turbines within a power plant and the distance between wind power plants determine the level of spatial or geographic diversity within a wind power plant or region, respectively. Thus, wind power plants located farther apart will experience more "smoothing" of the variability of the output of their resources due to high levels of geographic diversity. This smoothing effect will generally reduce the impact of system-wide ramp events.

The PSCO wind plants are shown in descending isolation in Table XVII. COLG and PONN, the weakest contributors to PSCO ramp events, are shown to be the most isolated from the other wind power plants which are confined to northeastern Colorado.

Table XVII - Spatial diversity of PSCO wind power plants

\begin{tabular}{|c|r|}
\hline $\begin{array}{c}\text { Most isolated PSCO wind } \\
\text { plants (descending) }\end{array}$ & Name \\
\hline 1 & COLG \\
\hline 2 & PONN \\
\hline 3 & SGCA \\
\hline 4 & CEDC \\
\hline 5 & PEET \\
\hline 6 & LOGA \\
\hline
\end{tabular}

The impact of geographic diversity was more profound when considering the correlations of rates of change between wind plants. The rates of change are the ten-minute step changes from one period to another. Interestingly, these step changes are better correlated during ramp events than during all times. The correlations increase further during more extreme ramp events. During the top 40 ramp events, a negative correlation between Colorado Green and Logan develops. Although fairly weak $(r=-$ $0.05)$, with this much data even very weak correlations are statistically significant. 

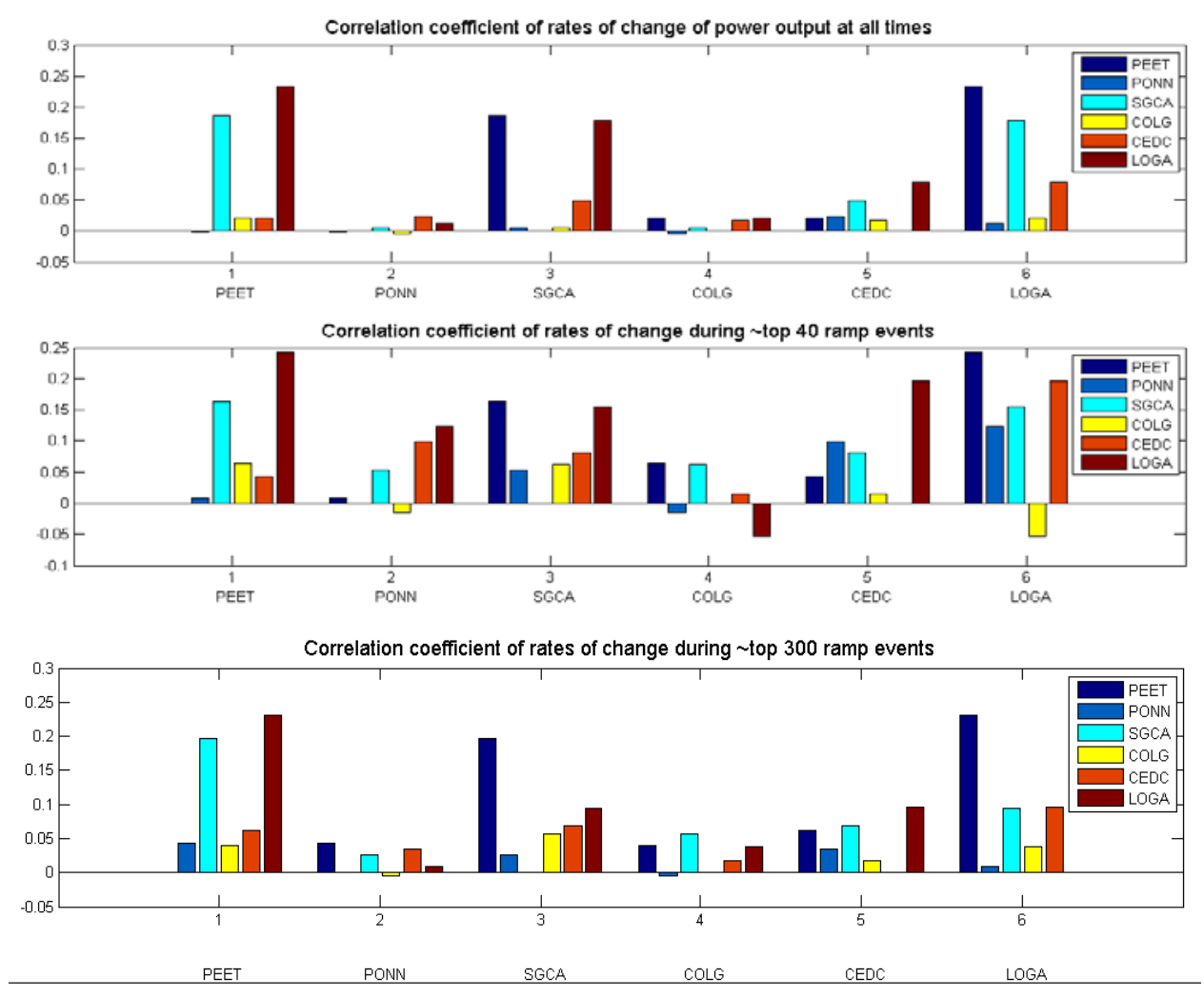

Figure 20 - Step change correlations for PSCO during all times and ramp events

In [6], it was shown that wind power correlations decay exponentially with increasing distances and that the rate of decay increases with decreasing levels of averaging in the time series data. Thus, correlations between ten-minute averaged power outputs, as above, will decay more quickly than for hourly averages, but much more slowly than for one-minute data. It is therefore important to consider the resolution of data when presenting correlation and whether wind power forecasts for production or specifically for predicting ramps are considering the same resolutions.

Since weather systems moving across the PSCO region will bring similar meteorological conditions to different wind power plants at different times, it is useful to compare the correlations between wind power plants several periods earlier or later. With this in mind, the team considered a geographictemporal analysis at various time lags and leads. Results from two plants were examined with this approach. Figure 21 shows correlations between Cedar Creek (CEDC) and other plants at various time shifts. Similarly, Figure 22 shows temporally shifted correlations between Logan (LOGA) and other selected plants. In Figure 21, the strongest correlation between Cedar Creek and PONN is found with PONN leading Cedar Creek by 60 minutes. In Figure 22, the strongest correlation between Logan and PONN is found with PONN leading Logan by 90 minutes. Considering that the prevailing winds in the region are from west to east and recalling the order of wind plants from above (west to east- PONN, CEDC, PEET, LOGA, and SGCA), one can see strong agreement with expected cross-correlations in the figures at temporal shifts. COLG was excluded from this analysis due to the weak correlations with all other plants. 


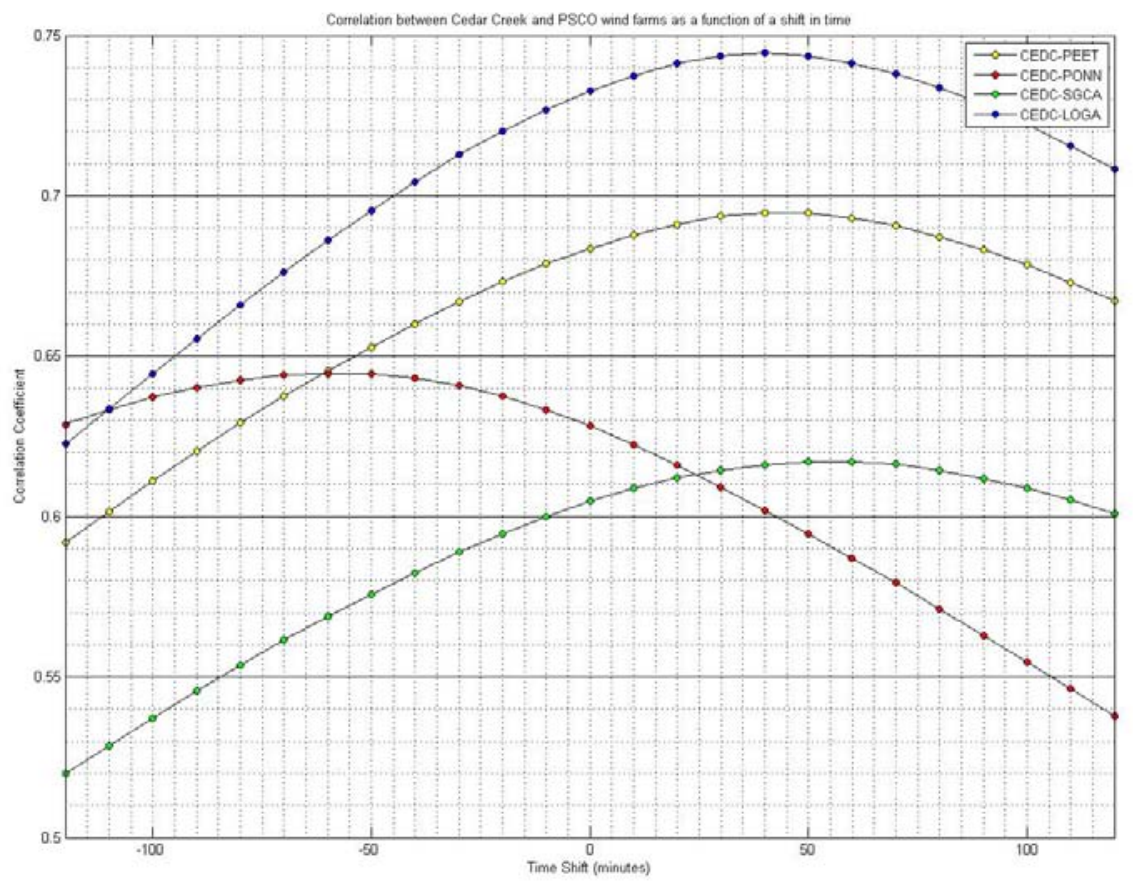

Figure 21 - Cross-correlations between Cedar Creek and PSCO wind plants as a function of a temporal shift

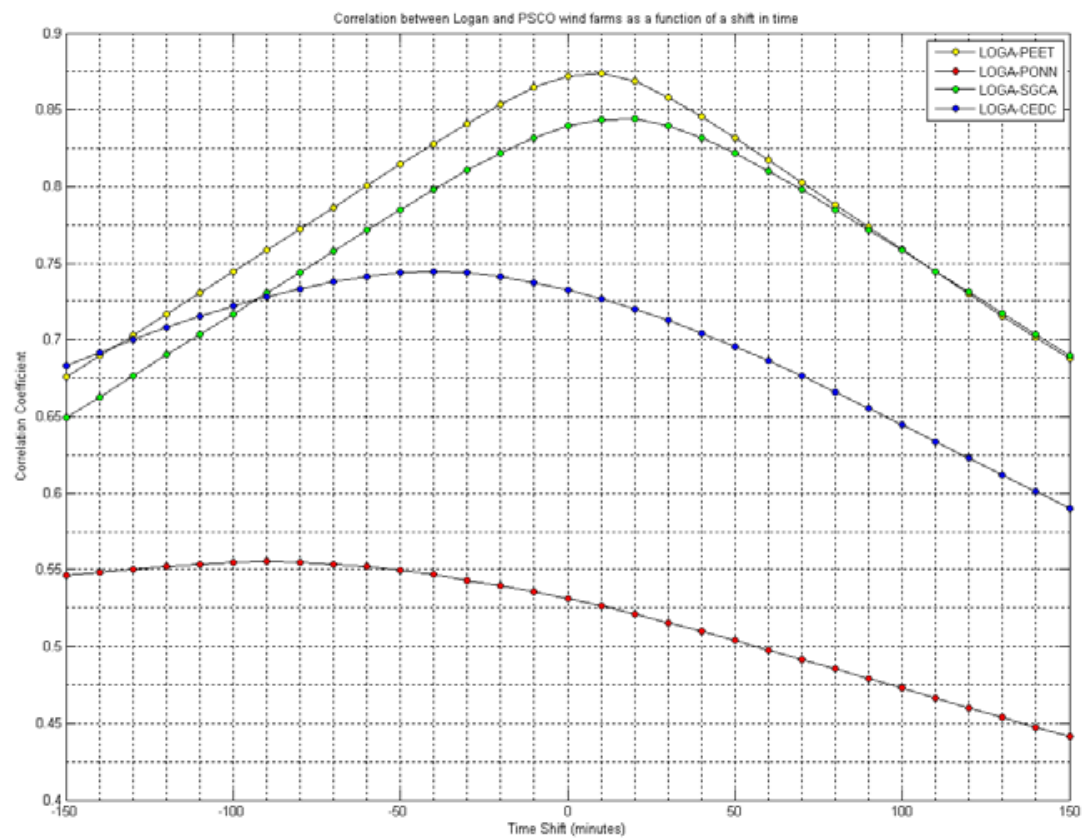

Figure 22 - Cross-correlations between Logan and PSCO wind plants as a function of a temporal shift

The temporally dependent cross-correlations between wind plants during ramp events are more important than during all times. As these extreme events move through a region, they bring rapid, turbulent changes for short durations. Lower correlations of power outputs, though difficult to see at the resolution shown in Figure 19 above, are quite evident in comparing Figure 22 and Figure 23 at a 
time shift of zero. However, the sensitivity of the cross-correlations to the temporal shift is more pronounced during ramp events compared to all times, as shown in Figure 23 and Figure 24 . This suggests that there is some benefit in using outlying wind power plants' power output during short time scales and at different lead times for different plant combinations to warn of expected wind ramping behavior system-wide. Figure 24 shows that in some cases, as with LOGA and CEDC, the highest correlation can change from leading to lagging. Lastly, this suggests that there is added benefit for utilizing modified output statistics in forecasting and the usefulness of having a centralized forecasting operation. The benefits of centralizing forecasting operations to take advantage of correlations between upstream and downstream wind power plants are key conclusions from other studies [12].

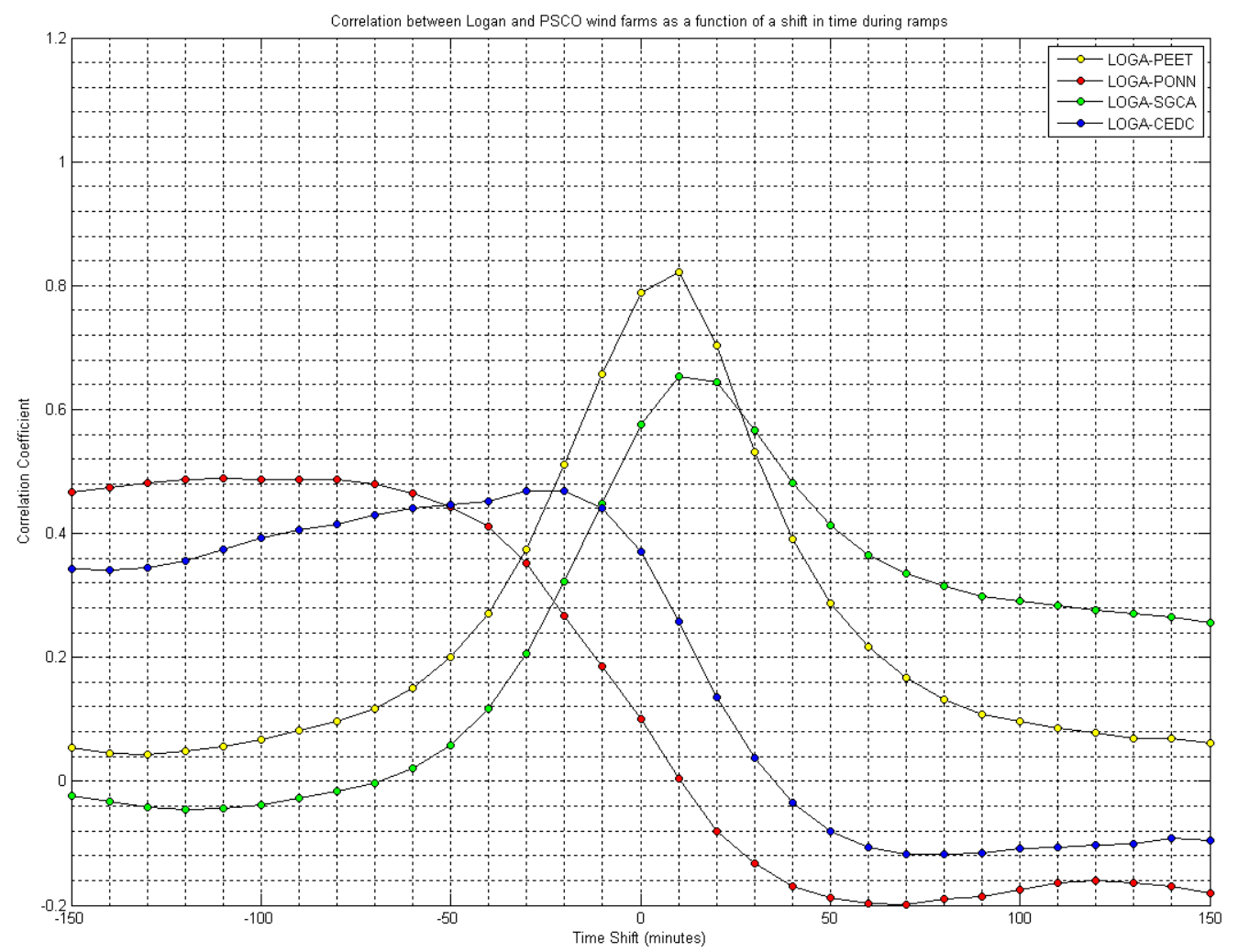

Figure 23 - Cross-correlations between Logan and PSCO wind plants as a function of a temporal shift during ramp periods 

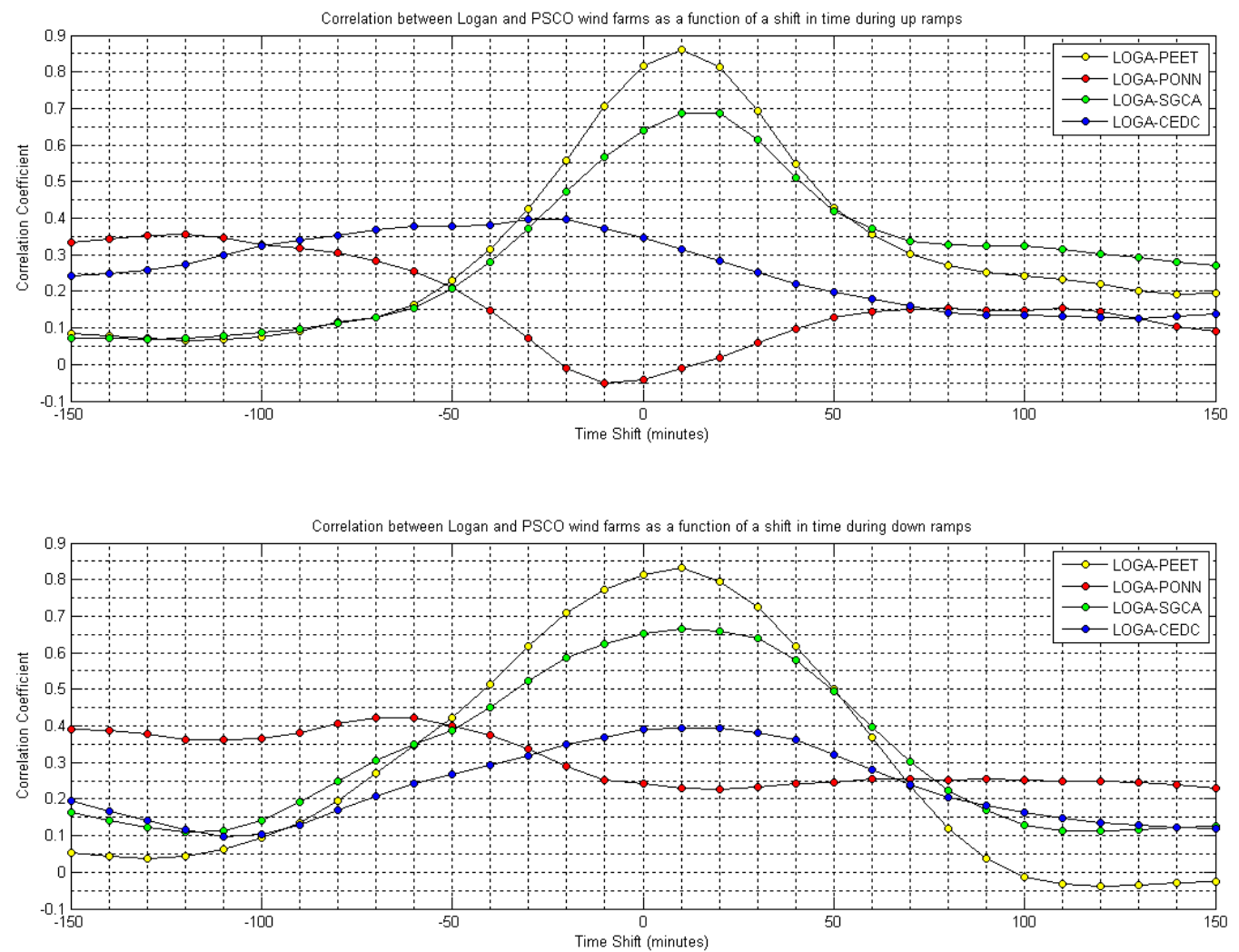

Figure 24 - Cross-correlations between Logan and PSCO wind plants as a function of time shift during system-wide up- and down-ramps

B. SPS

Similar correlation analyses were performed for SPS. In Figure 25, cross-correlations between selected SPS wind power plants and the system-wide total output of these wind power plants were compared. In comparison to Figure 19 for PSCO, Figure 25 shows more distinct deterioration of cross-correlations during ramping events as compared to all times. This may be due to better data quality for SPS. The behavior of the correlations during all ramp events very closely follows the results during up-ramp events. This reflects the findings in total numbers of up-ramps compared to down-ramps. 

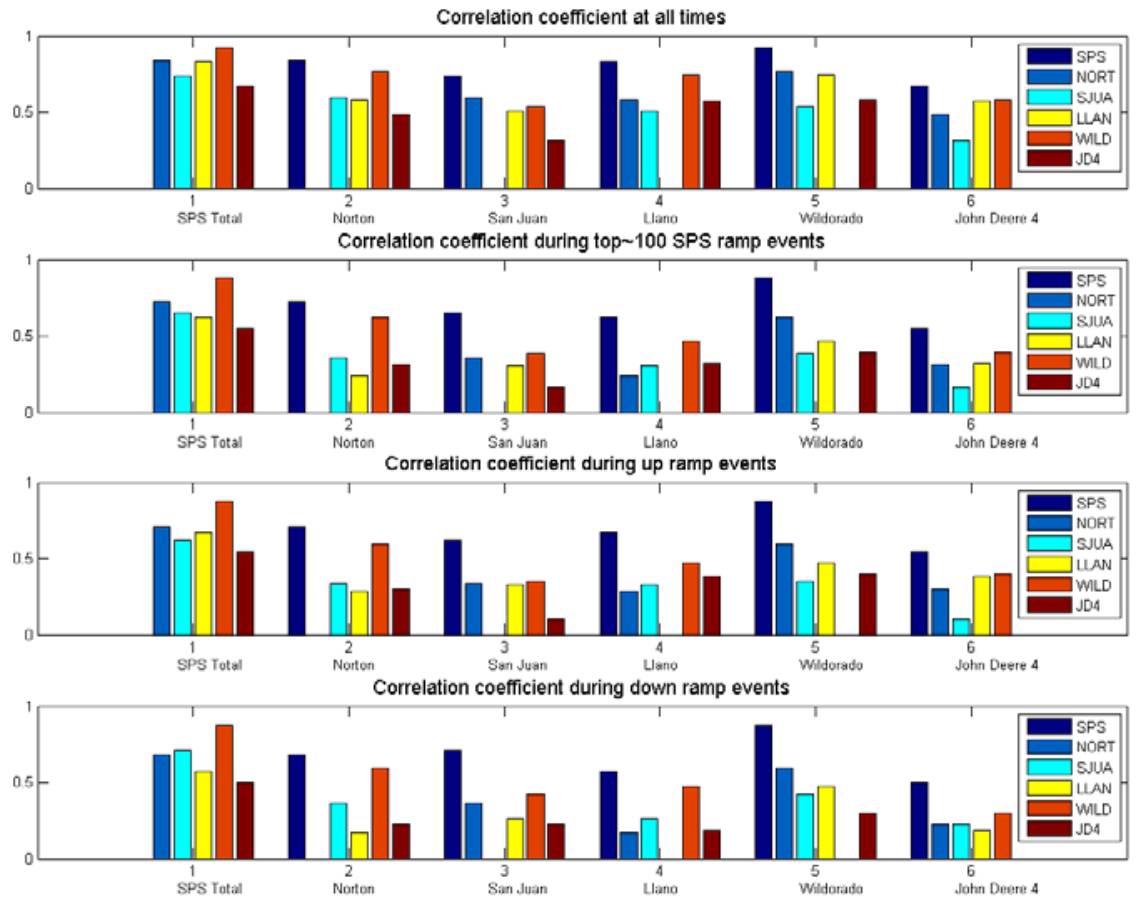

Figure 25 - Correlations between SPS wind power plants during ramp periods and all times

The cross-correlations for select SPS wind power plant step-changes mirrored the findings from PSCO as shown in Figure 26. Step change correlations are greater during periods of ramp events, but decay with distance much faster than correlations of power output. This figure is slightly skewed by showing system-wide results; however, the correlations between any wind power plant and the system-wide results are more telling than cross-correlations between other individual wind power plants. Table XVIII shows the distances between the SPS wind plants and Figure 27 shows the relationship between correlation and distance for all times. You can see that increasing distances correspond to lower correlation; however, this plot is also showing more noise around this trend. It is important to remember that the level of decay is dependent on the resolution of the data, and that higher resolution (i.e., shorter intervals) will generally show a greater level of decay with distance. 

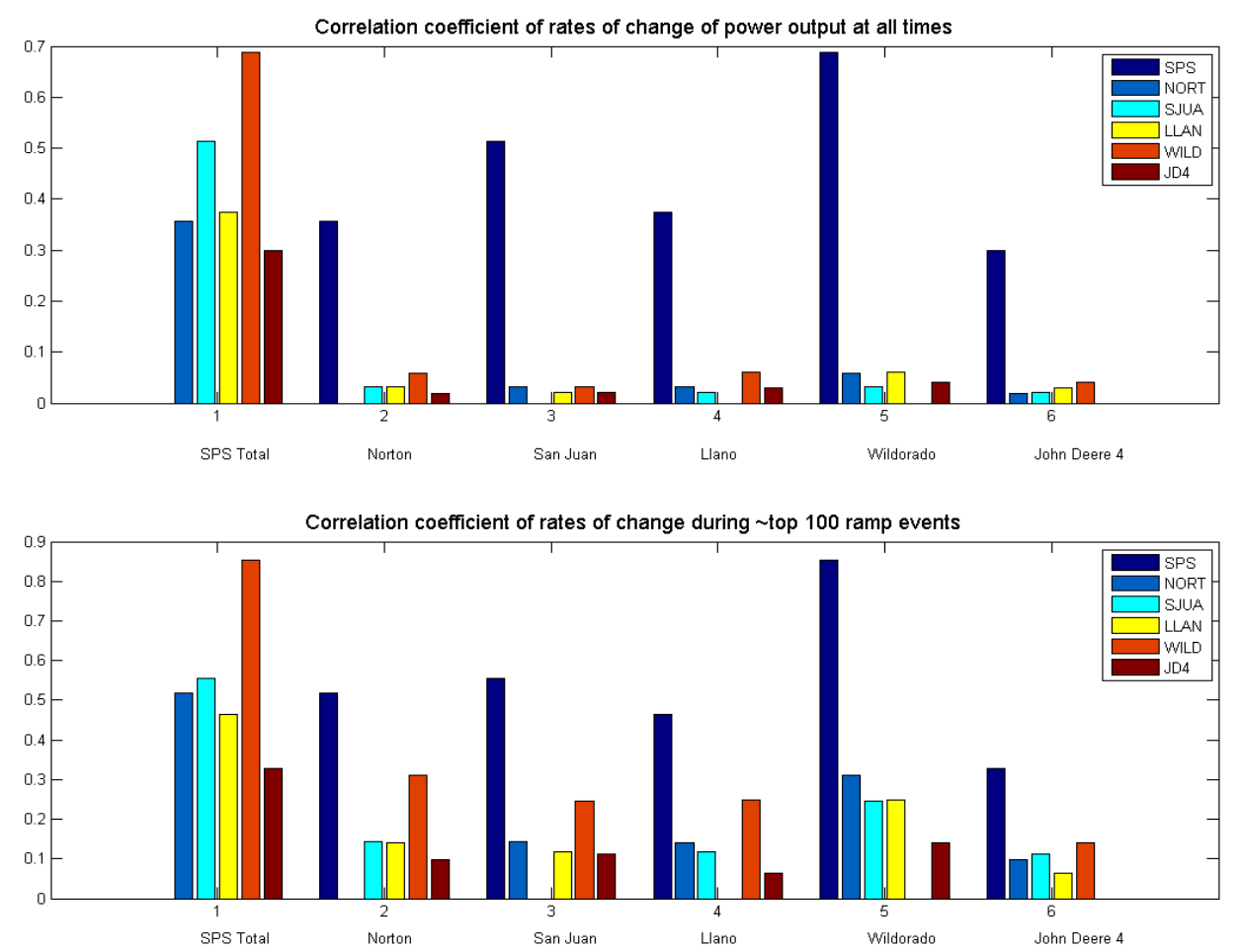

Figure 26 - Step change correlations for PSCO during all times and ramp events

Table XVIII - Distances between SPS wind plants

\begin{tabular}{|c|c|c|c|c|c|c|c|c|c|c|c|c|c|}
\hline $\begin{array}{l}\text { Distance } \\
\text { between SPS } \\
\text { wind plants } \\
\text { (miles) }\end{array}$ & NCAP & JD1_2 & JD3 & JD4 & JD5_6 & JD7_8 & JD9_10 & JD10_11 & SJWD & LLANO & WILD & HPWD & SUNR \\
\hline $\begin{array}{l}\text { Norton.Caprock, } \\
80 \mathrm{MW}\end{array}$ & 0 & 149 & 152 & 148 & 132 & 109 & $\overline{111}$ & 96 & 76 & 124 & 63 & 106 & 106 \\
\hline $\begin{array}{l}\text { JDWind1_2, } 20 \\
\text { MW }\end{array}$ & 149 & 0 & 8 & 9 & 21 & 40 & 41 & 55 & 220 & 72 & 96 & 80 & 45 \\
\hline JDWind3, $10 \mathrm{MW}$ & 152 & 8 & 0 & 4 & 28 & 42 & 42 & 57 & 222 & 68 & 96 & 76 & 47 \\
\hline $\begin{array}{l}\text { JDWind4, } 79.8 \\
\text { MW }\end{array}$ & 148 & 9 & 4 & 0 & 26 & 39 & 38 & 53 & 218 & 65 & 93 & 73 & 42 \\
\hline $\begin{array}{l}\text { JDWind5_6, } 20 \\
\text { MW }\end{array}$ & 132 & 21 & 28 & 26 & 0 & 30 & 34 & 45 & 206 & 76 & 85 & 79 & 36 \\
\hline $\begin{array}{l}\text { JDWind7_8, } 20 \\
\text { MW }\end{array}$ & 109 & 40 & 42 & 39 & 30 & 0 & 6 & 16 & 180 & 52 & 56 & 50 & 6 \\
\hline JDWind9, $10 \mathrm{MW}$ & 111 & 41 & 42 & 38 & 34 & 6 & 0 & 15 & 180 & 47 & 55 & 45 & 5 \\
\hline $\begin{array}{l}\text { JDWind10_11, } \\
20 \text { MW }\end{array}$ & 96 & 55 & 57 & 53 & 45 & 16 & 15 & 0 & 165 & 49 & 40 & 41 & 11 \\
\hline $\begin{array}{l}\text { SJuanWind, } 120 \\
\text { MW }\end{array}$ & 76 & 220 & 222 & 218 & 206 & 180 & 180 & 165 & 0 & 181 & 126 & 162 & 175 \\
\hline Llano, $80 \mathrm{MW}$ & 124 & 72 & 68 & 65 & 76 & 52 & 47 & 49 & 181 & 0 & 62 & 19 & 48 \\
\hline $\begin{array}{l}\text { Wildorado, } 161 \\
\text { MW }\end{array}$ & 63 & 96 & 96 & 93 & 85 & 56 & 55 & 40 & 126 & 62 & 0 & 43 & 50 \\
\hline $\begin{array}{l}\text { HighPlainsWinds, } \\
10 \mathrm{MW}\end{array}$ & 106 & 80 & 76 & 73 & 79 & 50 & 45 & 41 & 162 & 19 & 43 & 0 & 45 \\
\hline Sunray1, $9 \mathrm{MW}$ & 106 & 45 & 47 & 42 & 36 & 6 & 5 & 11 & 175 & 48 & 50 & 45 & 0 \\
\hline
\end{tabular}




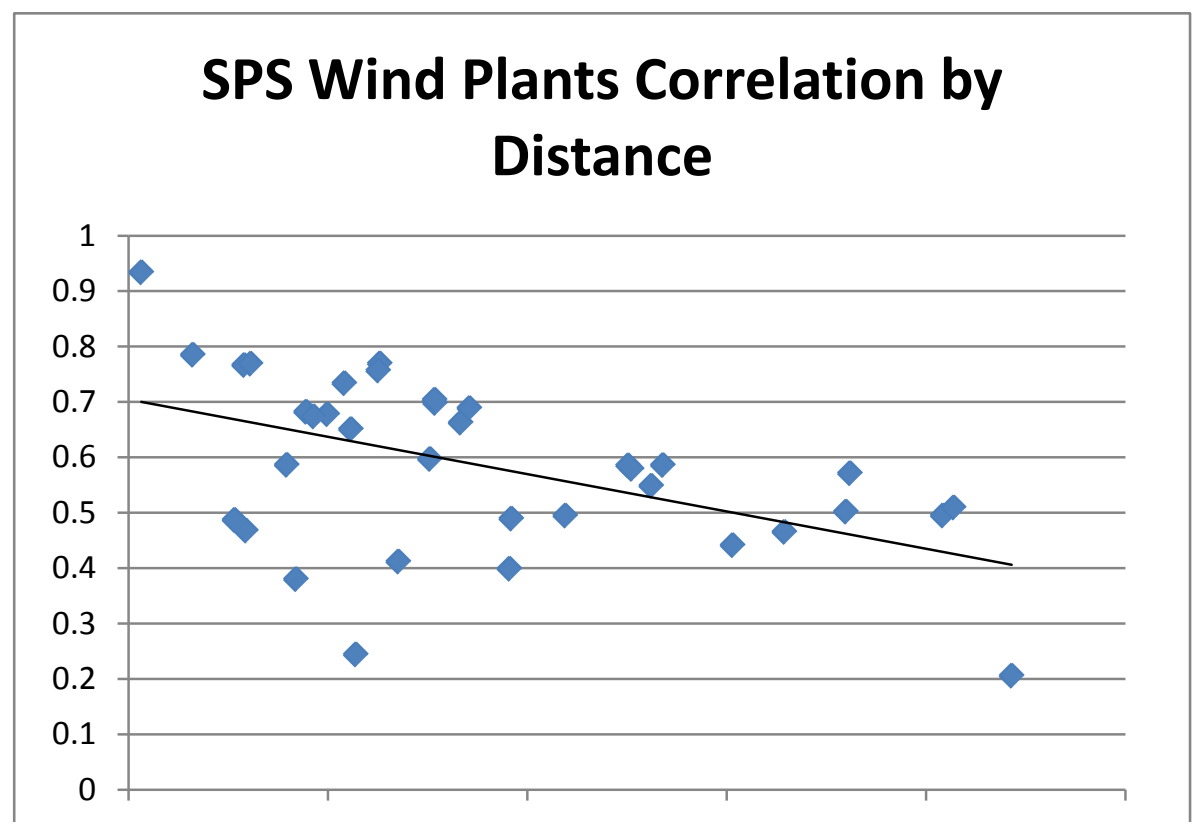

Figure 27 - Correlation coefficient for 10-min avgs by distance for SPS wind plants

\section{Conclusions}

Wind power is a growing resource in the United States and elsewhere. As utilities and system operators introduce greater penetrations, the operational impacts become more apparent. Most utilities and ISOs are now using wind power forecasting as a means to integrate more wind power on the system reliably and efficiently. As more of industry begins to use wind power forecasting in day-to-day operations, they also understand the importance of wind power forecasting during ramp periods. To better forecast these events, it is important to know the characteristics of these events on the particular system. The ramp events have certain days or periods in which they occur more frequently. They also have different contributions at different times depending on the geographical dispersion of wind plants, or wind plant correlation with load. These types of characteristics will vary from region to region depending on local weather patterns, geographic diversity, topography, site layout, and other factors.

The analysis in this report looks at past wind and load data to show characteristics of ramp events. Analysis showed statistics on number of ramps, when they most occur, and volatility. It also showed how plants correlated to each other in time and space, and how different factors contributed to wind and net load ramps. By comparing different ramp statistics, it was shown that geographic diversity lessened the per-unit impact on ramps. All of this information becomes valuable for areas preparing for higher wind penetrations and for improvements in ramp forecasting. 


\section{References}

1. R Wiser, M Bolinger, 2008 Wind Technologies Market Report 2008, Washington, D.C., U.S. Department of Energy, 2008.

2. J. Charles Smith, Michael Milligan, Edgar Demeo, and Brian Parsons, "Utility Wind Integration and Operating Impact State of the Art," IEEE Trans. Power Systems, vol. 22, pp. 900-908, Aug. 2007.

3. Enernex Corporation and Wind Logics, Inc., "Xcel Energy and the Minnesota Department of Commerce Wind Integration Study - Final Report," Sep. 2004.

4. Enernex Corporation, "Final Report: Wind Integration Study for Public Service Company of Colorado," May 2006.

5. Enernex Corporation, "Wind Integration Study for Public Service of Colorado Addendum Detailed Analysis of 20\% Wind Penetration," Dec. 2008.

6. Y. Wan, Wind Power Plant Behaviors: Analysis of Long-Term Wind Power Data, National Renewable Energy Lab., Golden, CO, NREL/TP-500-36651, 2004.

7. K. Parks, "Value to Real-Time Operations," Utility Wind Integration Group Forecasting Workshop, February 2009.

8. Southwest Power Pool. www.spp.org

9. Midwest ISO. www.midwestiso.org

10. FERC Order, Standard Market Design (SMD), Notice of Proposed Rulemaking (NOPR), July 31, 2002

11. Matlab. www.mathworks.com

12. GE Energy, The Effects of Integrating Wind Power on Transmission System Planning, Reliability, and Operations: Report on Phase 2, prepared for the New York State Energy Research and Development Authority, Mar. 2005. 


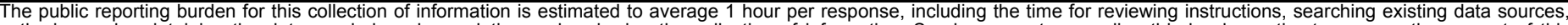

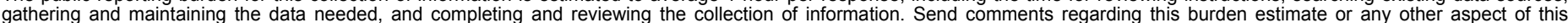

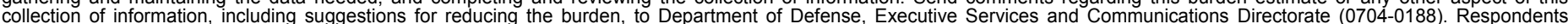

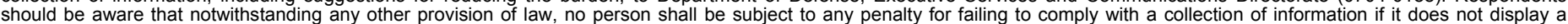

should be aware that notwithstanding

PLEASE DO NOT RETURN YOUR FORM TO THE ABOVE ORGANIZATION.

\begin{tabular}{l|l|l|l} 
1. REPORT DATE $(D D-M M-Y Y Y Y)$ & 2. & REPORT TYPE & 3. DATES COVERED (FrOm - TO)
\end{tabular}

December 2009

4. TITLE AND SUBTITLE

Wind Plant Ramping Behavior
Technical Report

5a. CONTRACT NUMBER

DE-AC36-08-GO28308

5b. GRANT NUMBER

5c. PROGRAM ELEMENT NUMBER

5d. PROJECT NUMBER

NREL/TP-550-46938

5e. TASK NUMBER

WER8.5102

5f. WORK UNIT NUMBER
7. PERFORMING ORGANIZATION NAME(S) AND ADDRESS(ES)

National Renewable Energy Laboratory

1617 Cole Blvd.

Golden, CO 80401-3393
8. PERFORMING ORGANIZATION REPORT NUMBER

NREL/TP-550-46938

9. SPONSORING/MONITORING AGENCY NAME(S) AND ADDRESS(ES)

10. SPONSOR/MONITOR'S ACRONYM(S) NREL

11. SPONSORING/MONITORING AGENCY REPORT NUMBER

12. DISTRIBUTION AVAILABILITY STATEMENT

National Technical Information Service

U.S. Department of Commerce

5285 Port Royal Road

Springfield, VA 22161

13. SUPPLEMENTARY NOTES

14. ABSTRACT (Maximum 200 Words)

With the increasing wind penetrations, utilities and Independent System Operators (ISO) are quickly trying to understand the impacts on system operations and planning. This report focuses on ramping imapcts within the Xcel

service region.

\section{SUBJECT TERMS}

Wind; integration; ramping; operations; AGC; balancing; ISO; Xcel; area control error; ACE; RPS

\begin{tabular}{|c|c|c|}
\hline \multicolumn{3}{|c|}{ 16. SECURITY CLASSIFICATION OF: } \\
\hline $\begin{array}{l}\text { a. REPORT } \\
\text { Unclassified }\end{array}$ & $\begin{array}{l}\text { b. ABSTRACT } \\
\text { Unclassified }\end{array}$ & $\begin{array}{l}\text { c. THIS PAGE } \\
\text { Unclassified }\end{array}$ \\
\hline
\end{tabular}

\begin{tabular}{l|l} 
17. LIMITATION & 18. \\
OF ABSTRACT & OF PAGES \\
UL &
\end{tabular}

19a. NAME OF RESPONSIBLE PERSON

19b. TELEPHONE NUMBER (Include area code) 